\title{
Elastoplastic and fracture behaviour of semi-crystalline polymers under multiaxial stress states
}

\author{
João P. Manaia, Francisco A. Pires, Abílio M. P. de Jesus \\ Department of Mechanical Engineering, Faculty of Engineering, University of Porto, Rua Dr. Roberto Frias, s/n 4200-465, Porto, \\ Portugal. \\ joaomanaia@netcabo.pt,fpires@fe.up.pt,ajesus@fe.up.pt
}

\begin{abstract}
The deformation behaviour and fracture mechanisms of highdensity polyethylene (HDPE), polypropylene (PP) and polyamide 6 (PA 6) are investigated experimentally under different stress states and at different crosshead speeds of 1, 20 and $200 \mathrm{~mm} / \mathrm{min}$. Fracture surface morphologies were investigated in a series of specimens tested at $200 \mathrm{~mm} / \mathrm{min}$ under combined tension/shear loading at three different loading angles $\left(\alpha=0^{\circ}, 30^{\circ}\right.$ and $\left.90^{\circ}\right)$ at room temperature (RT) and $50^{\circ} \mathrm{C}$. In addition, the effects of notch profile radii (stress triaxiality) on HDPE, PP and PA 6 fracture behaviour have been studied at RT, using flat and cylindrical notched specimens. Specimens' geometries were carefully designed to achieve various loading conditions and allowing to explore initial stress triaxialities ranged from 0 in pure shear loading $\left(\alpha=0^{\circ}\right)$ to a maximum of 0.84 for flat notched specimens with radius of $5 \mathrm{~mm}$. The yield load shows an explicit dependency on temperature and crosshead speed. The fracture surfaces analysed reveals damage mechanisms such as crazing, void and cavitation formation. Two or more mechanisms are predominant, which means that the stresses along fracture process are not uniform.
\end{abstract}

KEYWORDS. Semi-crystalline polymers; Fracture; SEM; Stress triaxiality; Multiaxial loading; Butterfly specimen.

\section{OPEN ACCESS}

Citation: Manaia, J. P., Pires, F. A., Jesus, M. P. de J., Fracture morphologies of semi crystalline polymers under different stress states, Frattura ed Integrità Strutturale, 47 (2019) 82-103.

Received: 03.11.2018

Accepted: 20.11.2018

Published: 01.01.2019

Copyright: (C) 2019 This is an open access article under the terms of the CC-BY 4.0, which permits unrestricted use, distribution, and reproduction in any medium, provided the original author and source are credited.

\section{INTRODUCTION}

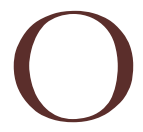

ne of the most relevant subjects of applied polymers science is the understanding of the deformation mechanisms and the fracture properties of semi-crystalline polymers. Mechanical studies on semi-crystalline polymers show that properties such as tensile strength and elongation at break are associated with the deformation and rearrangement of crystalline and amorphous phases. The imposed loadings draw crystalline lamellae and amorphous phase into viscoelastic and plastic deformation. The deformation of semi-crystalline polymers is complex, multistage and are strongly dependent on the underlying structure as well as external parameters such as applied stress, strain rate, temperature and pressure and they are often accompanied by volume change during their viscoplastic deformations $[1,2]$. 
The state of stress, such as the one included by the presence of notches, is one factor that controls the occurrence of extended yielding or brittle failure, even though such polymers behaves as ductile under tensile tests over wide temperature and strain-rate ranges [3]. Many experimental results have shown that the material's fracture changes under different loading conditions. Among different damage mechanisms, the stress triaxiality has been recognized as one of the most important fracture controlling factors [4]. Bridgman [5] conducted experiments on a variety of metallic alloys discovering that an increase in stress triaxiality results in a corresponding increase in damage nucleation and growth. The location of high hydrostatic stress is thought to favour craze initiation. Crazing happens due to the nucleation of microvoids in regions of stress concentrations, normal to the maximum principal stress. These voids do not coalesce to form cracks (as in metals) since highly stretched molecular chains, or fibrils, stabilize this process to create crazes, thus craze consists of a web of interpenetrating voids and polymer fibrils [6].

In the current experimental investigation, different stress triaxiality levels are induced by different notch radii in tensile specimens. The triaxial stress state effects on deformation and fracture morphology were examined by means of tests using cylindrical and flat notched specimens with different curvature radii in order to set different triaxial stress triaxialities in the median cross-section, from 0.39 for the cylindrical notched specimen with radius of $30 \mathrm{~mm}$ to 0.84 for the flat notched specimens with radius of $5 \mathrm{~mm}$. In addition, combined loading tests were performed with butterfly specimens and Arcan apparatus, resulting stress triaxialities ranging between 0 to 0.58 , being those specimens also analysed in terms of deformation behavior as well as fracture surfaces appearance by Scanning Electron Microscopy (SEM).

Polymers have a quite significant level of change in physical and mechanical properties over a relatively small change in temperature, which are largely determined by their molecular structure and the resulting bonds. Tijssens et al. [7] showed the importance that temperature plays in crazing of amorphous polymers. Elongation at failure typically increases when the temperature increases and polymer behaves in a much more viscous manner. At relatively low temperatures, the craze damaging mechanisms widens very rapidly. The failure will occur faster, thus behaviour becomes more brittle. At higher temperatures a more spread-out craze zone will develop. Since a craze widens slower as temperature increases, more crazes tend to be initiated.

The main purpose of present research is to investigate and describe the morphologies and mechanisms of fracture of HDPE, PP and PA 6 materials tested at crosshead speeds of $200 \mathrm{~mm} / \mathrm{min}$, using two complementary experimental approaches: one combining tension/shear loading at three different loading angles $\left(\alpha=0^{\circ}, 30^{\circ}\right.$ and $\left.90^{\circ}\right)$ at $\mathrm{RT}$ and $50^{\circ} \mathrm{C}$, carried out on butterfly specimens and another imposing a triaxial stress state on cylindrical and flat notched specimens with different curvature radii at RT. The mechanisms of fracture are reported and discussed with respect to the different loading conditions with emphasis on the relation between loading angles and temperature on biaxial loading, and notch effects on notched specimens. Also, the deformation response was examined under different stress states, crosshead speeds of 1,20 and 200 $\mathrm{mm} / \mathrm{min}$ and two different temperatures (RT and $50^{\circ} \mathrm{C}$ ), in order to compare the yield load, temperature responses and neck propagation for the three materials. The present paper is organized as follows. In Section 2, we present the investigated material, the different specimen geometries and the mechanical testing protocols. In Section 3, the experimental results are displayed and discussed. Further, specimens fracture morphologies are analysed, by means of SEM micrographs in Section 4. Some concluding remarks are finally given in Section 5.

\section{EXPERIMENTAL DETAILS}

$\mathrm{T}$ he materials covered in this paper are the HDPE, PP and PA 6, three semi-crystalline thermoplastics. Complex specimen geometries, a designed injection mould made of steel and a biaxial testing apparatus were specifically designed for this research. All the specimens used in this study were manufactured by injection moulding. In order to compare the deformation behaviour (e.g. yielding, necking) under different temperatures and strain rates. The laboratory tests were performed at crosshead speeds of 1, 20 and $200 \mathrm{~mm} / \mathrm{min}$ at two different temperatures (room temperature and $50^{\circ} \mathrm{C}$ ). All specimens were loaded using a tensile test machine until fracture. SEM observations of fracture surfaces, were performed only for specimens tested at crosshead speed of $200 \mathrm{~mm} / \mathrm{min}$.

\section{Materials}

The materials used in the present studied are the Dow ${ }^{\mathrm{TM}}$ HDPE KT $10000 \mathrm{UE}$, high density polyethylene resin provided by Dow Chemical Company (Dow); Sabic ${ }^{\circledR}$ PP PHC27, a semi-crystalline polymer and a multipurpose polypropylene impact copolymer, provided by Saudi Basic Industries Corporation (SABIC) and Promyde ${ }^{\circledR}$ B30 PMID, a Polyamide 6 impact modified, provided by Nurel Engineering Polymers. 
Differential Scanning Calorimetry (DSC) tests were performed on 8 to $10 \mathrm{mg}$ of solid granulates of HDPE, PP and PA 6 at a heating rate of $10{ }^{\circ} \mathrm{C} / \mathrm{min}$, using a TA Instruments DSC Q20. The reproducibility of the measurements was verified by a second run. The crystal weight fraction $\left(\varnothing_{c \nu}\right)$ is calculated as the ratio of the measured melting enthalpy $\left(\Delta \mathrm{H}_{f}\right)$ and the theoretical melting enthalpy of a perfect crystalline polymer $\left(\Delta \mathrm{H}_{f}^{0}\right)$ taken equal to $293 \mathrm{~J} / \mathrm{g}, 209 \mathrm{~J} / \mathrm{g}$ and $188 \mathrm{~J} / \mathrm{g}$, respectively for HDPE, PP and PA $6[8,9]$ :

$$
\varnothing_{c \nu}=\frac{\Delta \mathrm{H}_{f}}{\Delta \mathrm{H}_{f}^{0}}
$$

Crystallinity weight fractions of approximately $55.1 \%, 40.4 \%$ and $49.1 \%$, respectively for HDPE, PP and PA 6 were found. Also, the melting temperatures $\left(\mathrm{T}_{m}\right)$ were confirmed to be $139.6^{\circ} \mathrm{C}, 170.7^{\circ} \mathrm{C}$ and $227.4^{\circ} \mathrm{C}$, respectively. The DSC tests also allowed to disclosure the glass transition temperature $\left(\mathrm{T}_{g}\right)$ of PA 6 , which was $54 \pm 2{ }^{\circ} \mathrm{C}$. HDPE and PP glass transition temperatures were not confirmed since they show negative values and our DSC tests only covered positive temperatures. However according to literature [9], HDPE and PP materials show glass transition temperatures the order of -100 and $-20^{\circ} \mathrm{C}$, respectively.

\section{Specimens' geometries}

Triaxial stress states were reproduced by means of tests using cylindrical and flat notched specimens with different curvature radii in order to set different triaxial stress states in the median cross-section, from 0.39 for the cylindrical notched specimen with a radius of $30 \mathrm{~mm}$ to 0.84 for the flat notched specimen with a radius of $5 \mathrm{~mm}$. In addition, a butterfly specimen was designed for biaxial tensile/shear loading, using an Arcan apparatus. The biaxial testing allows exploring initial stress triaxialities ranged between 0 and 0.58 .

Geometries and dimensions of the cylindrical notched specimens for uniaxial tensile experiments, are described in Fig. 1. The geometric parameters were chosen in order to set different stress states in the gauge section. The minimal cross section diameter is equal to $5 \mathrm{~mm}$, but the length of the non-uniformly reduced section is assigned with two different notch radii: $\mathrm{R}=30 \mathrm{~mm}$ and $\mathrm{R}=5 \mathrm{~mm}$. Both ends of cylindrical notched specimens were machined with $\mathrm{M} 14$ threads for mounting in the testing machine.
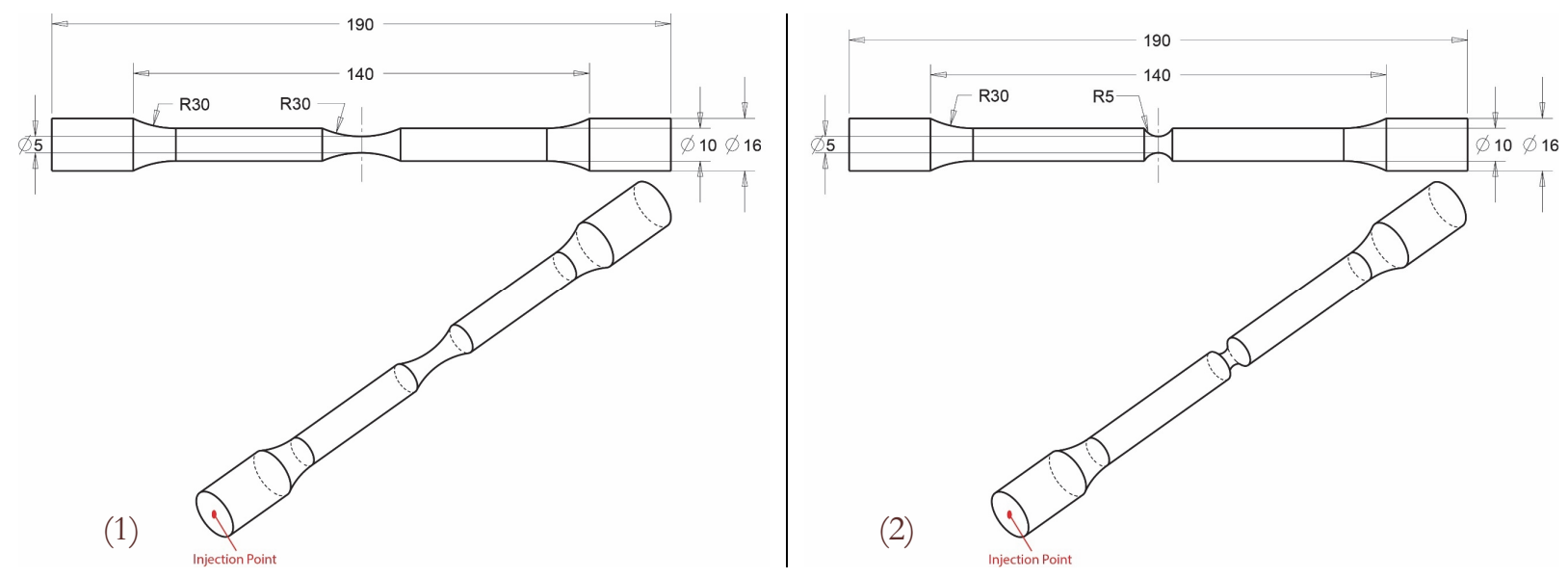

Figure 1: Cylindrical notched specimens: (1) radius of $30 \mathrm{~mm}$ and (2) radius of $5 \mathrm{~mm}$. (Dimensions in millimeters).

The main reasons to include notches in the specimen geometry is to confine the plastic deformation and the onset of fracture processes into the notched region [10]. A formula for the stress triaxiality was first derived by Bridgman, who analysed the stress distribution in cylindrical metal specimens with different notches. Bridgman's formula involves the relationship between the smallest cross section $a_{0}$ and the notch radius, $R$. At the centre of the median cross-section the stress triaxiality ratio, $\eta$, is maximum and is defined as the ratio of the hydrostatic stress $\sigma_{b}$ and the von Mises equivalent stress $\sigma_{e q}$, which according the Bridgman formula results in $[4,11]$ : 


$$
\eta=\frac{\sigma_{b}}{\sigma_{e q}}=\frac{1}{3}+\ln \left(1+\frac{a_{0}}{2 \mathrm{R}}\right)
$$

where $R$, is the notch radius, $a_{0}$ is the minimum and initial radius of the centre of the median cross-section and ln, is the naeperian logarithm. If $R \rightarrow 0$ the equation above is not valid, and if $R \rightarrow \infty$, the geometry of the specimen tends to that of a smooth cylindrical for which stress triaxiality ratio is $\eta=1 / 3$ [4,12]. Bridgman formula was revisited by Bao and Wierzbicki using finite element simulation, being proposed a corrected equation with a coefficient of $\sqrt{2}$ [4]:

$$
\eta=\frac{1}{3}+\sqrt{2} \ln \left(1+\frac{a_{0}}{2 R}\right)
$$

An initial minimum radius $a_{0}$ of $2.5 \mathrm{~mm}$ was chosen for the two geometries. The initial stress triaxiality ratio is equal to 0.39 and 0.64 for $\mathrm{R}=30$ and $\mathrm{R}=5$ specimens, respectively. As expected the stress triaxiality ratio increases inversely to the notch radius of specimens[4].

The shapes and dimensions of the flat notched specimens, for uniaxial positive loading path, are illustrated in Fig. 2. Two different notch radii: $\mathrm{R}=30 \mathrm{~mm}$ and $\mathrm{R}=5 \mathrm{~mm}$, are assigned, similarly to the cylindrical geometry.
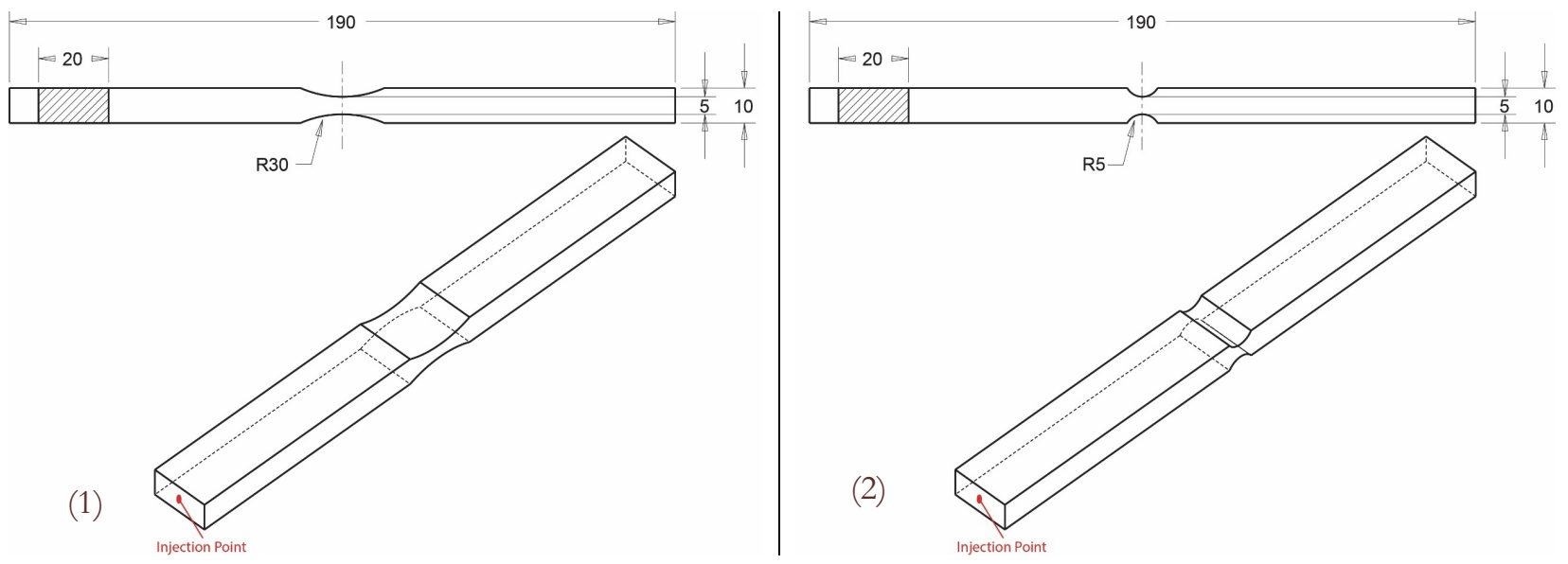

Figure 2: Flat notched specimens: (1) radius of $30 \mathrm{~mm}$ and (2) radius of $5 \mathrm{~mm}$. (Dimensions in millimeters).

The Bridgman stress triaxiality formula was derived for the point inside the notch of a flat notched plane strain specimen by Bai et al. [4]. Test results on 2024-T351 aluminium alloy and finite element simulations corroborated this formula. At the centre of the median cross-section the stress triaxiality ratio $\eta$ is maximum and is given by the following equation [4]:

$$
\eta=\frac{\sqrt{3}}{3}+\left(1+2 \ln \left(1+\frac{t}{4 R}\right)\right)
$$

where $t$ is the ligament thickness of the flat notched specimen, $R$ is the notch radius and $\ln$ is the naeperian logarithm [4]. An initial minimum ligament thickness $t$ of $5 \mathrm{~mm}$ was chosen for the two geometries. Equation above implies that the range of stress triaxiality at the centre of a plane strain specimen is $\eta \geq 1 / \sqrt{3}$. The initial stress triaxiality ratio is equal to 0.62 and 0.84 for $\mathrm{R}=30 \mathrm{~mm}$ and $\mathrm{R}=5 \mathrm{~mm}$ notch radii, respectively.

Butterfly specimens under combined tensile/shear loading were investigated according three different loading angles, $\alpha$ $=0^{\circ}$ (pure shear), $\alpha=30^{\circ}$ (both combined shear and tension) and $\alpha=90^{\circ}$ (pure tension) using specific designed butterfly specimen. The specimen dimensions and shape are shown in Fig. 3. Note that a similar specimen shape was designed by Bai [4], for 2024-T351 aluminium alloy and A710 steel. 


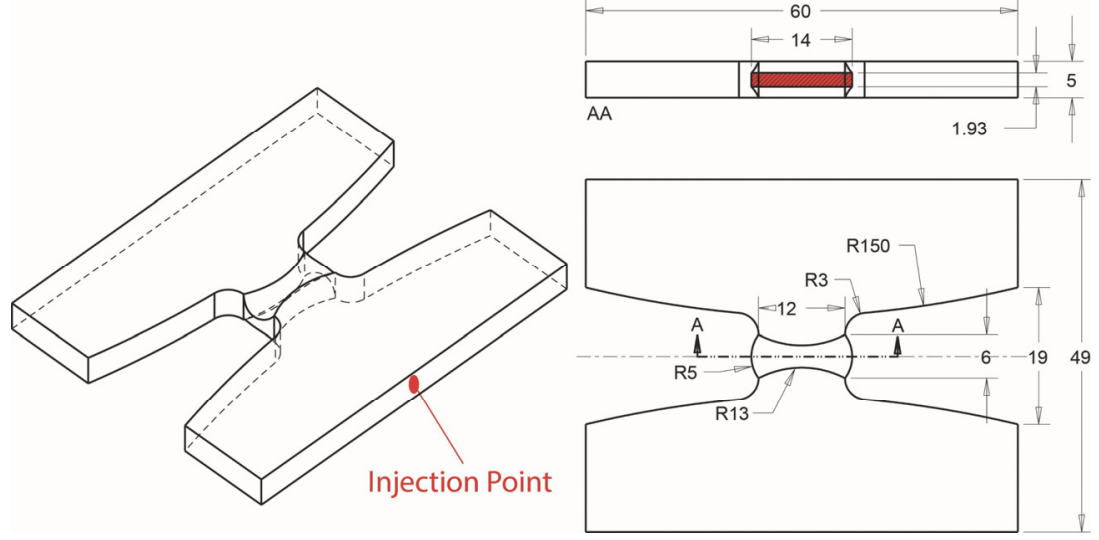

Figure 3: Butterfly specimen shape, dimensions in millimeters.

The relevance of this geometry was analysed and optimized by 3D FE calculations. The FE calculations confirmed that the specimen shoulders deform elastically, while the central gauge section exhibits large plastic deformations. Also, the shoulders dimensions provide sufficient gripping area. The complex loft surface in the gauge section of the specimen, lowers the likelihood of fracture in the vicinity of the specimen boundaries. Consequently, the onset of fracture processes is confined to initiate near the specimen centre in the gauge section under all loading combinations and at the same time the specimen experiences a wide range of stress states (stress triaxiality). The analytical formula for initial stress triaxiality was derived by Dunand and Mohr, in their study to optimize butterfly specimen for the multiaxial ductile fracture experiments on sheet metals [13]:

$$
\eta=\frac{\operatorname{sign}(\sigma)}{\sqrt{3}+12(\tau / \sigma)^{2}}
$$

The stress triaxiality is zero for shear dominant loading $(\sigma / \tau \rightarrow 0)$ while it approaches its maximum value of $\eta=1 / \sqrt{3}$ as the pure tension becomes dominant $(\sigma / \tau \rightarrow \infty)$ [13]. To sum up, the biaxial loading allows exploring initial stress triaxialities ranged from 0 for pure shear $\alpha=0^{\circ}$ (Fig. 4 (2)) to 0.58 for pure tension $\alpha=90^{\circ}$ (Fig. 4 (3)) and 0.19 for $\alpha=30^{\circ}$ (both combined shear and tension) (Fig. 4 (4)).
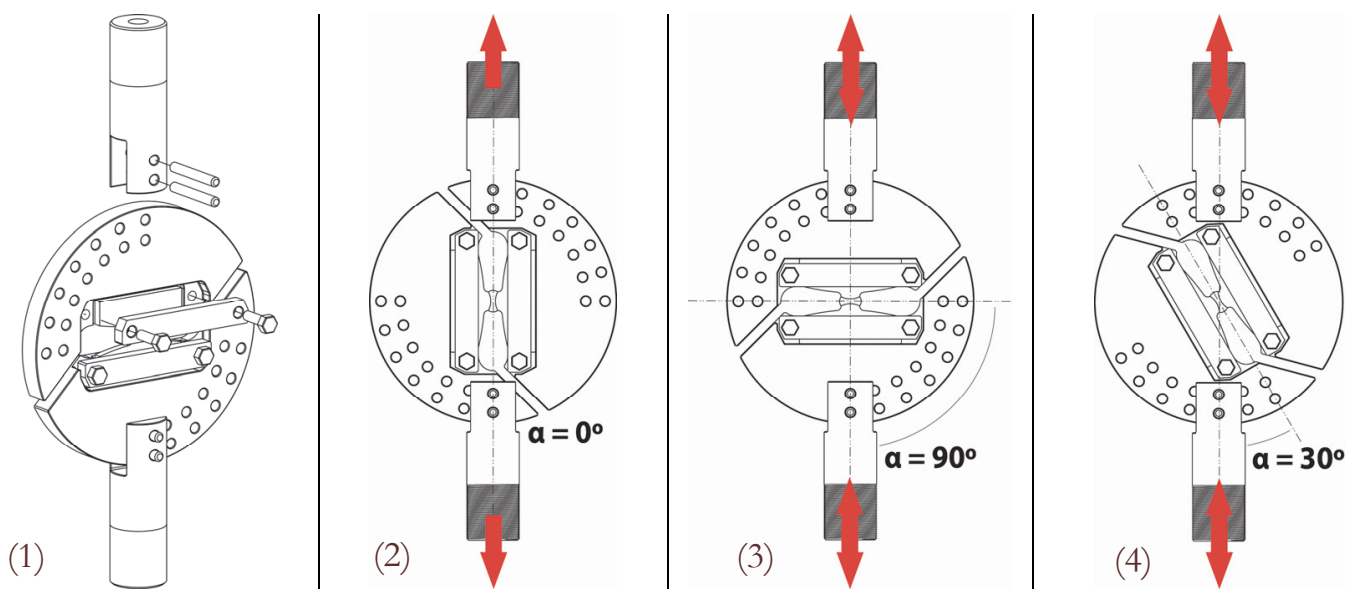

Figure 4: Butterfly specimen at four different loading angles: (1) designed arcan apparatus with the butterfly specimen, (2) $\alpha=0^{\circ}$ (pure shear), (3) $\alpha=90^{\circ}$ (pure tension) and (4) $\alpha=30^{\circ}$ (combined shear and tension).

For the present biaxial experiments, an arcan apparatus, was designed and manufactured (Fig. 4 (1)). The designed arcan apparatus is a modification based on the work by Doyoyo and Wierzbicki [14], which in turn is based on the original specimen presented by Arcan et al. to study the biaxial failure of unidirectional fiber-reinforced composites [15]. The loading 
apparatus consists of two pairs of plane semi-circular loading steel plates and the butterfly specimen placed in between. The array of pin holes locations on the outer edge of the loading plates provide a range of biaxial loading angles $\alpha$. The biaxial loading angle can be varied in steps of $15^{\circ}$ from $0^{\circ}$ to $90^{\circ}$. Two removable clamps positioned the butterfly specimen in the symmetry plane of the arcan apparatus. Two screws at each side provided sufficient clamping pressure. The four pins, two in opposite side, prevents any rotation or misalignment either vertical or horizontal during the biaxial loading. Therefore, the out-of-plane displacement is avoided, as suggested Mohr and Doyoyo [16].

\section{Testing macbines}

The mechanical tests at RT were carried out by a servohydraulic MTS 810 universal testing machine, with a $10 \mathrm{KN}$ load cell, while the mechanical tests at $50{ }^{\circ} \mathrm{C}$ were performed inside the Instron environmental chamber (temperature rating from $150{ }^{\circ} \mathrm{C}$ to $+350{ }^{\circ} \mathrm{C}$ ), with the biaxial apparatus attached to the Instron 3367 loading machine. The tests were performed after the specimen stabilizing in the chamber for 20 minutes at the required temperature $\left(50{ }^{\circ} \mathrm{C}\right)$ in order to obtain sufficiently constant cross-sectional temperature (assure thermal equilibrium). In this work, RT means that the air temperature was $21^{\circ} \mathrm{C}$ (deviation $\pm 2{ }^{\circ} \mathrm{C}$ ) and relative humidity of $55 \%$ (deviation $\pm 10 \%$ ), which was the same atmosphere in which all specimens were conditioned.

During the tests, a MTS 634.25 axial extensometer with a gauge length of $50 \mathrm{~mm}$, was used to measure the elongation of both cylindrical and flat notched specimens, whereas for biaxial tests the displacements were continuously measured by internal actuator LVDT. Both displacement and force were recorded at an appropriate frequency, depending on crosshead speed. A batch of five specimens (5 repetitions) for each crosshead speed (1, 20 and $200 \mathrm{~mm} / \mathrm{min})$, specimen geometry and loading angles $\left(\alpha=0^{\circ}, \alpha=30^{\circ}\right.$ and $\left.\alpha=90^{\circ}\right)$ were tested at RT, while at $50^{\circ} \mathrm{C}$ a batch of three specimens at two crosshead speeds ( 1 and $200 \mathrm{~mm} / \mathrm{min}$ ) and at the same loading angles as in RT, were performed.

SEM observations were performed by the field-emission scanning electron microscopy, instrument FEI Quanta 400 FEG ESEM, with a nominal resolution of $<2 \mathrm{~nm}$. The secondary electron (SE) mode allowed a detailed examination of the semicrystalline structure. The intensity of the digitized micrographs is defined on a 256 greyscale[17]. The specimens were fixed with double coated carbon tape which, is also used for dissipation of the electron beam charge and heat. All samples were also coated with Platinum before scanning with SEM using Jeol IFC 1600 coating machine. Tab. 1, depicts the total number of SEM observations.

\begin{tabular}{|c|c|c|c|c|c|c|c|}
\hline \multicolumn{2}{|c|}{ Specimens Geometry } & \multicolumn{2}{|c|}{ HDPE } & \multicolumn{2}{|c|}{$\mathrm{PP}$} & \multicolumn{2}{|c|}{ PA 6} \\
\hline \multirow{2}{*}{ Flat notched } & Radius $=5$ & \multicolumn{2}{|c|}{$\mathrm{RT}=1$} & \multicolumn{2}{|c|}{$\mathrm{RT}=1$} & \multicolumn{2}{|c|}{$\mathrm{RT}=1$} \\
\hline & Radius $=30$ & \multicolumn{2}{|c|}{$\mathrm{RT}=1$} & \multicolumn{2}{|c|}{$\mathrm{RT}=1$} & \multicolumn{2}{|c|}{$\mathrm{RT}=1$} \\
\hline \multirow{2}{*}{ Cylindrical notched } & Radius $=5$ & \multirow{2}{*}{\multicolumn{2}{|c|}{$\begin{array}{l}\mathrm{RT}=1 \\
\mathrm{RT}=1\end{array}$}} & \multirow{2}{*}{\multicolumn{2}{|c|}{$\begin{array}{l}\mathrm{RT}=1 \\
\mathrm{RT}=1\end{array}$}} & \multirow{2}{*}{\multicolumn{2}{|c|}{$\begin{array}{l}\mathrm{RT}=1 \\
\mathrm{RT}=1\end{array}$}} \\
\hline & Radius $=30$ & & & & & & \\
\hline \multirow{3}{*}{$\begin{array}{c}\text { Combined } \\
\text { tensile/shear loading }\end{array}$} & $\alpha=0^{\circ}$ & $\mathrm{RT}=1$ & $50^{\circ} \mathrm{C}=1$ & $\mathrm{RT}=1$ & $50{ }^{\circ} \mathrm{C}=1$ & $\mathrm{RT}=1$ & $50^{\circ} \mathrm{C}=1$ \\
\hline & $\alpha=30^{\circ}$ & $\mathrm{RT}=1$ & $50^{\circ} \mathrm{C}=1$ & $\mathrm{RT}=1$ & $50{ }^{\circ} \mathrm{C}=1$ & $\mathrm{RT}=1$ & $50^{\circ} \mathrm{C}=1$ \\
\hline & $\alpha=90^{\circ}$ & $\mathrm{RT}=1$ & $50{ }^{\circ} \mathrm{C}=1$ & $\mathrm{RT}=1$ & $50{ }^{\circ} \mathrm{C}=1$ & $\mathrm{RT}=1$ & $50^{\circ} \mathrm{C}=1$ \\
\hline
\end{tabular}

Table 1: Total number of specimens used in SEM observations (crosshead speed of $200 \mathrm{~mm} / \mathrm{min}$ ).

\section{TEST RESULTS - DEFORMATION BEHAVIOUR}

he mechanical response of HDPE, PP and PA 6, were examined under different stress states until fracture. In order to investigate a wider range of stress states and strain rates, tensile tests were performed on flat notched and cylindrical notched specimens with different notch radii at different crosshead speeds of 1,20 and $200 \mathrm{~mm} / \mathrm{min}$. In addition, biaxial loading tests at three loading angles, were performed at room temperature and $50{ }^{\circ} \mathrm{C}$.

ISO 527-1 defines the yield stress as the first stress at which an increase in strain occurs without an increase in stress [18]. As a convention in this paper, and hereinafter, from the load displacement curves the yield load is considered as the first maximum force at which an increase in displacement occurs without an increase in load, when noticeable.

Tensile flat notched and cylindrical notched tests

Despite belonging to semi-crystalline polymers with crystallinity percentage from DSC scans of 55.1\%, 40.4\% and 49.1\%, respectively for HDPE, PP and PA 6, their mechanical behaviour are somewhat different. The load-displacement curves of 
PA 6, HDPE and PP at three crosshead speeds are displayed in Figs. 5 and 6, for each specimen geometry. The loaddisplacement responses were compared to ensure repeatability of the results. The scatter between the tests batches was relatively small.
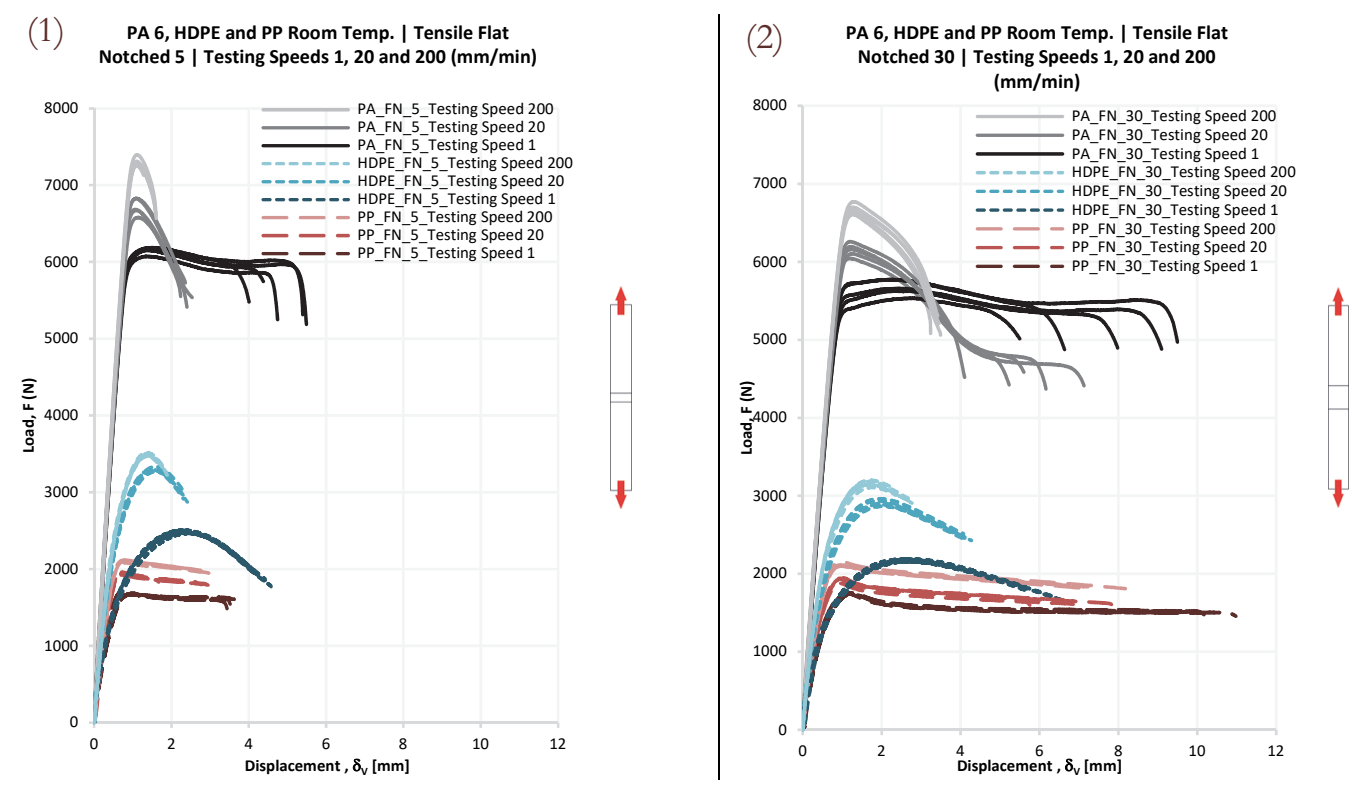

Figure 5: Tensile load-displacement curves of (1) flat notched $\mathrm{R}=5$ and (2) flat notched $\mathrm{R}=30$ specimens (PA 6, HDPE and PP at RT).
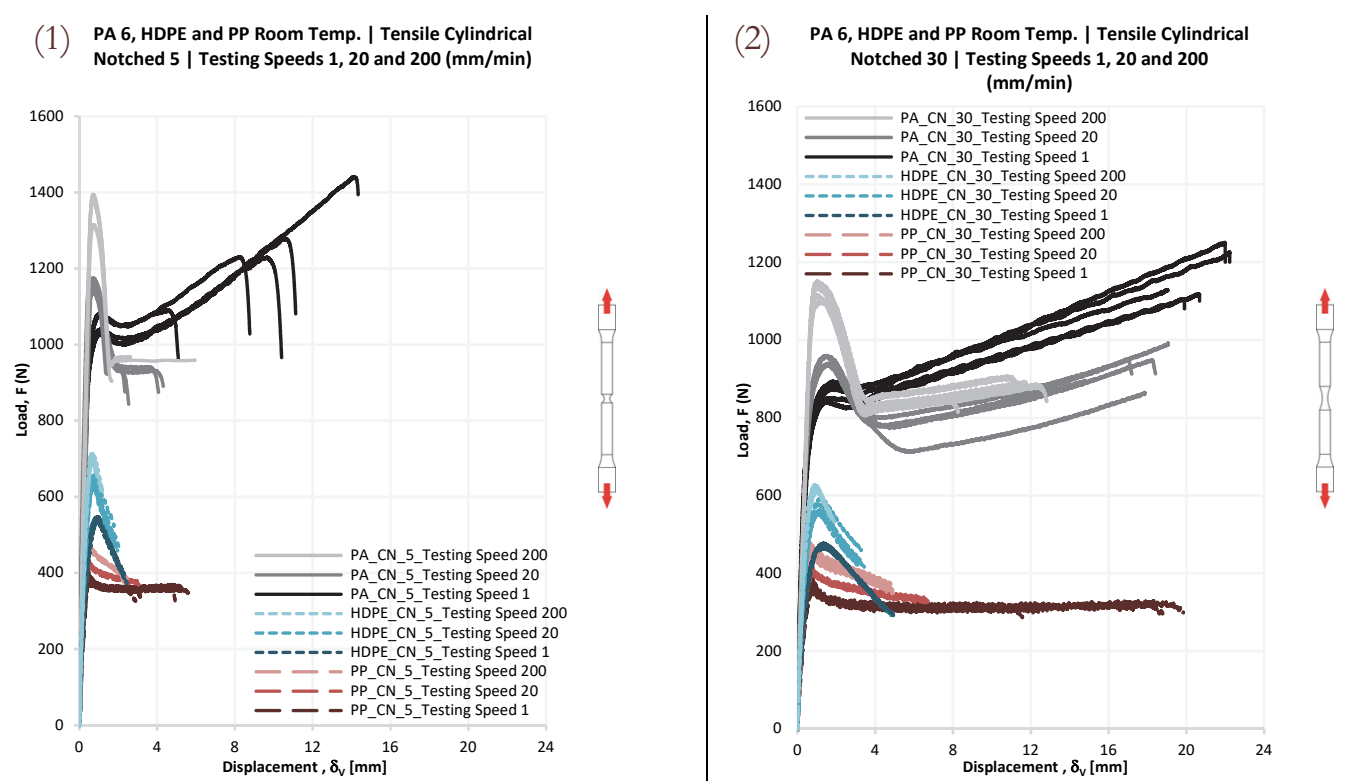

Figure 6: Tensile load-displacement curves of (1) cylindrical notched $\mathrm{R}=5$ and (2) cylindrical notched $\mathrm{R}=30$ specimens (PA 6, HDPE and PP at RT).

Initially, the deformation is linear with the load increasing proportionally to the displacement. There is then a nonlinear region prior to yield load followed by yield, where the force reaches a maximum. It is observed that the yield load decreases with the reduction of testing speed and the corresponding displacement increases inversely. At higher crosshead speed, increases both the propensity of the material to form a clear and higher yield load at lower displacement values. At lower crosshead speeds, the polymer macromolecules have more time to induce an orderly alignment just enough to accept the increase in deformation. It is also clear the reduction of ductility as the crosshead speed increases exhibiting the material a more brittle behaviour. Higher crosshead speeds reduce the degree of chain relaxation, resulting in more preferred orientation [19]. The maximum/failure displacements achieved were for crosshead speeds of $1 \mathrm{~mm} / \mathrm{min}$. 
Tensile test results on cylindrical and flat notched specimens indicate that the presence of notch changes the loaddisplacement behaviour, despite of the same minimum cross section. The yield load increases with decreasing the specimen notch radii (increasing the stress triaxiality), whereas the corresponding displacement ductility decreases. This behaviour might be attributed to the notch strengthening effect since the notch induces radial and circumferential stresses in addition to the axial stress. These additional stresses could inhibit lamellar rotation toward axial direction; also alter the force acting on the crystalline lamellae, thereby altering their ability to participate in slip processes and delaying the onset of plastic deformation [20]. Beyond the yield load, the specimens gradually started to whiten. As the plastic deformation continued, the stress whitening became clearer and sets the shape changes (dilatation). Therefore, a neck started to form at the same location as onset of stress whitening. This characteristic was clearly noticeable among cylindrical notched specimens. Along with the stress whitening zone, the neck propagated through the notched section of the specimen during the deformation. Plastic dilation in polymers can be assumed to be related to damage. Such damage can be microvoids that grow from local irregularities of the molecular structure. With ongoing deformation, localisation grows to extremes, resulting in void nucleation, craze formation and catastrophic failure [21-23].

\section{Combined tensile/shear loading test}

Fig. 7 shows the results when a tensile vertical displacement is applied during biaxial loading, for HDPE, PP and PA 6. At $\mathrm{RT}$ and for all loading angles, the corresponding load-displacement behaviour shows the expected increase in initial yield force with increase in crosshead speed. It can be observed that the higher the loading angle (from $\alpha=0^{\circ}$ to $90^{\circ}$ ), the higher the load required to deform the specimens, is; whereas the displacement decreases. The simple physical explanation of this phenomenon is that semi-crystalline polymers become more difficult to deform when the molecules get closer to an aligned, stretched conformation [24]. At $\alpha=0^{\circ}$, pure shear, the material behaviour is completely different, the yield displacement is increased and there is large deformation (strain hardening) which means more ductile behaviour. The general shape of all curves, seems to be homothetic, for each biaxial loading angle exhibiting remarkably similar intrinsic behaviour and in the case of PA 6 the load-displacement curves overlap each other, for high plastic strains. This mechanical behaviour might indicate that there is a thermal softening associated with a progressive localization of heat sources at high crosshead speeds as observed by Wattrisse et al. [25]. The initial linear elastic response is followed by a nonlinear evolution, this nonlinearity increasing with applied crosshead speed.

At HDPE butterfly specimens with deformation, independently of the loading angle, near fracture point, the crazes, which are bridged by fibrils, open up and fracture occurs upon the failure of these fibrils, without causing cracking and global failure. A careful examination of the fractured specimens for each loading angle, indicates that cracks initiate at the centre of the gauge section in all the cases. However, it is difficult to determine directly from the experiments whether fracture starts from the middle thickness of the cross section or from the surface.

Fig. 7 also compares the load-displacement results from biaxial loading at RT with corresponding results in the temperature of $50{ }^{\circ} \mathrm{C}$. A decrease in the yield load or an increase yield load displacement are observed with an increase in temperature and a decrease in the crosshead speed. Similar conclusions on temperature dependence were obtained by Hartmann et al. [26], who performed uniaxial tension tests to the yield load on polypropylene dumbbell specimens as a function of temperature from 22 to $143^{\circ} \mathrm{C}$ at a strain rate of $2 / \mathrm{min}$. Therefore, temperature and strain rate have a clear influence on mechanical properties of semi-crystalline polymers. The displacement at failure also increases with an increase of temperature in the case of HDPE, however this tendency is not verified for PP and PA 6. In the case of PP, the displacements at RT and at $50{ }^{\circ} \mathrm{C}$ are almost equal and for PA 6 in general are greater at room temperature than at temperature of $50{ }^{\circ} \mathrm{C}$. Stress whitening was observed in the gauge section of butterfly specimens. The occurrence of stress whitening in HDPE was found to be dependent upon the temperature and strain rate.

PA 6 mechanical responses at RT are characterized by yield, softening and hardening, as the specimens are inelastically strained (Figs. 6 and 7). At crosshead speed of $200 \mathrm{~mm} / \mathrm{min}$, the test requires approximately 1 to $2 \mathrm{~s}$ and nearly adiabatic conditions exist due to insufficient time for significant heat transfer to occur. The remarkable softening of the material is observed after yield load due to combined result of strain softening and thermal softening. The softening ends where the load-displacement response is observed to level off even though the temperature in the specimen might continue to rise. Much of the observed effects of the increased crosshead speed on the post yield response of PA 6, was observed by Arruda et al. [27] on polymethylmethacrylate (PMMA). However, at temperature of $50^{\circ} \mathrm{C}$ the softening behaviour is not observed in Fig. 7, considering the same loading angle. At RT testing the imposed deformations might induce the change of material state, from glassy to glassy-rubbery (glass transition temperature) by increasing its internal temperature. The glass transition marks the onset of extensive molecular motion which is reflected in marked changes in properties, such as volume and stiffness. The material may be more easily deformed and become ductile [28]. On the other hand at temperature of $50^{\circ} \mathrm{C}$, 
PA 6 is already in its glass temperature state, although possible increase of internal material temperature due to deformation there is no change of state.

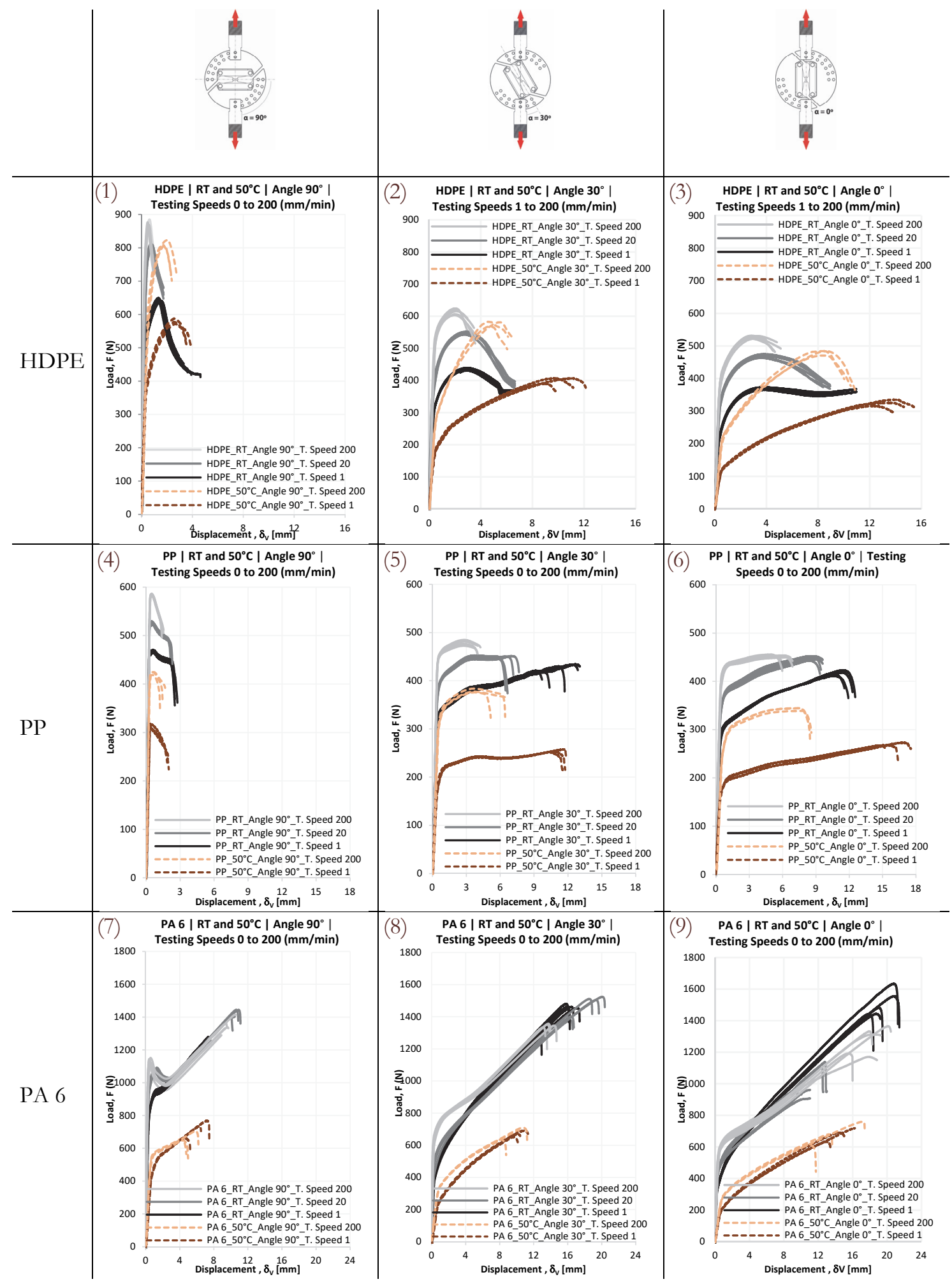

Figure 7: Load-displacement curves for HDPE, PP and PA 6 resulting from combined tension/shear loading at RT and $50{ }^{\circ} \mathrm{C}$ : influence of crosshead speeds for each loading angle. 
As a general rule, however, semi-crystalline polymers are used at temperatures between glass transition temperature and a practical softening temperature which lies above $T_{\mathrm{g}}$ and below $T_{m}$, these are the cases of HDPE and PP. In Figs. 5 to 7 , although the different stress states, loading angle conditions, the general shape of all curves for each material and test, seems to exhibit remarkably similar intrinsic behaviours, when compared with increase crosshead speed. At higher crosshead speed, increases the propensity of material to soften, however it is not so pronounced as in PA 6. It seems that in semi-crystalline polymers used at temperatures above $T_{\mathrm{g}}$ becomes more stables. Relatively to the molecular structure, HDPE has a long linear chain (lower degree of branching), therefore has stronger intermolecular forces. HDPE is chemically the closest in structure to PP, therefore similarities in load-displacement curves, are observed. However HDPE exhibits better mechanical properties [29].

\section{TEST RESUlTS - FRACTURE SURFACE MORPHOLOGIES}

Analysis of flat notched specimens fracture morphologies under tension at stress triaxialities between 0.62 and 0.84

11 flat notched specimens made of HDPE, PP and PA 6 experienced full section fracture under tension at crosshead
speed of $200 \mathrm{~mm} / \mathrm{min}$ and at RT. Fracture surfaces of representative specimens are displayed in Figs. 8 and 9.

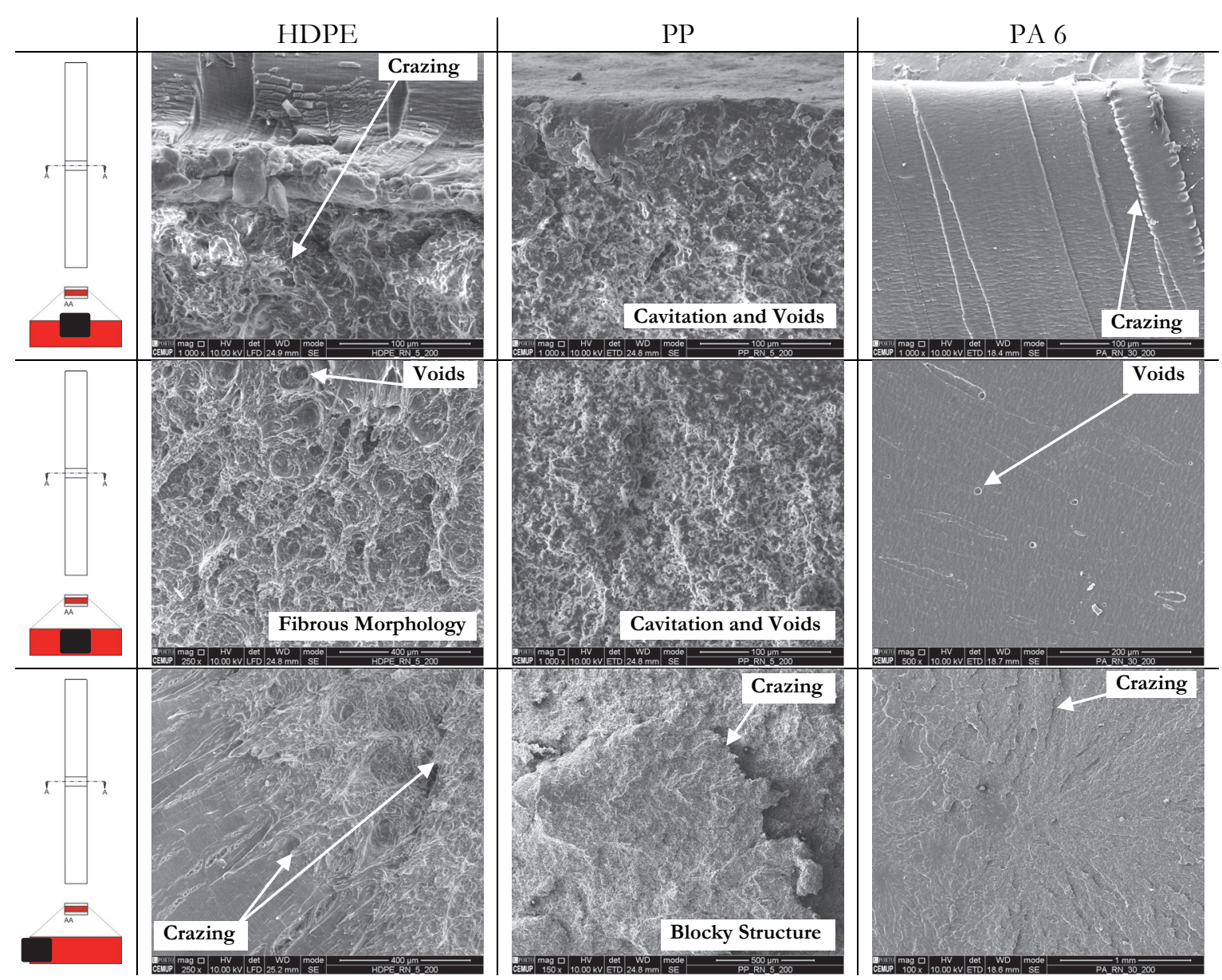

Figure 8: SEM fracture surfaces for flat notched specimens with $\mathrm{R}=5$, for HDPE, PP and PA 6. Note that in the first column the geometry of specimen and fracture surface location are indicated by the black square over the cross-section.

Qualitative SEM observations of HDPE fracture surfaces at several magnifications for flat notched specimens, $\mathrm{R}=5$ and $\mathrm{R}=30$, show the formation of an oriented texture of fibrous surface at the centre with a number of longer fibrils. At the centre, due to the higher stress triaxiality, occurs the initial fracture, while at the near surface, the fracture surface becomes more inhomogeneous, because that is the last region to fracture. It is believed that cavitation at centre, due to numerous 
voids ("cavities"), and crazing near surface are the dominant modes of deformation. Cavitation might precede crazing due to the formation of microfibrils of oriented chains that span around the faces of the voids. Studies on the development and growth of crazes in thermoplastic materials have indicated that crazing involves alignment, merging, and splitting of microfibrils and nucleation of micro-voids [30]. The difference between crazes and cavities is that the last one do not have an internal structure, thus are unable to transfer stress [19]. The presence of fibrous surface with fibrils pulled out in the fracture surface is an indicator of ductility.

It is observed that increasing the stress triaxiality, the fracture surface becomes more brittle and homogeneous, with less formation propensity of longer fibrous surface and more voids content. Dasari et al. [31] observed on their experiments on ethylene - propylene copolymers, wedge shaped micro-cracks parallel to the tensile direction on the surface of the deformed specimen. During tensile straining, the edges multiplied and the plastic flow around the edges led to their separation from the surrounding matrix leading to fibrillation type of fracture. An illustration of this is presented in Fig. 9, column HDPE at central and extremities near surface, due to high radius the material flows more extensively, besides that multiplication of wedges, crazing also occurred.

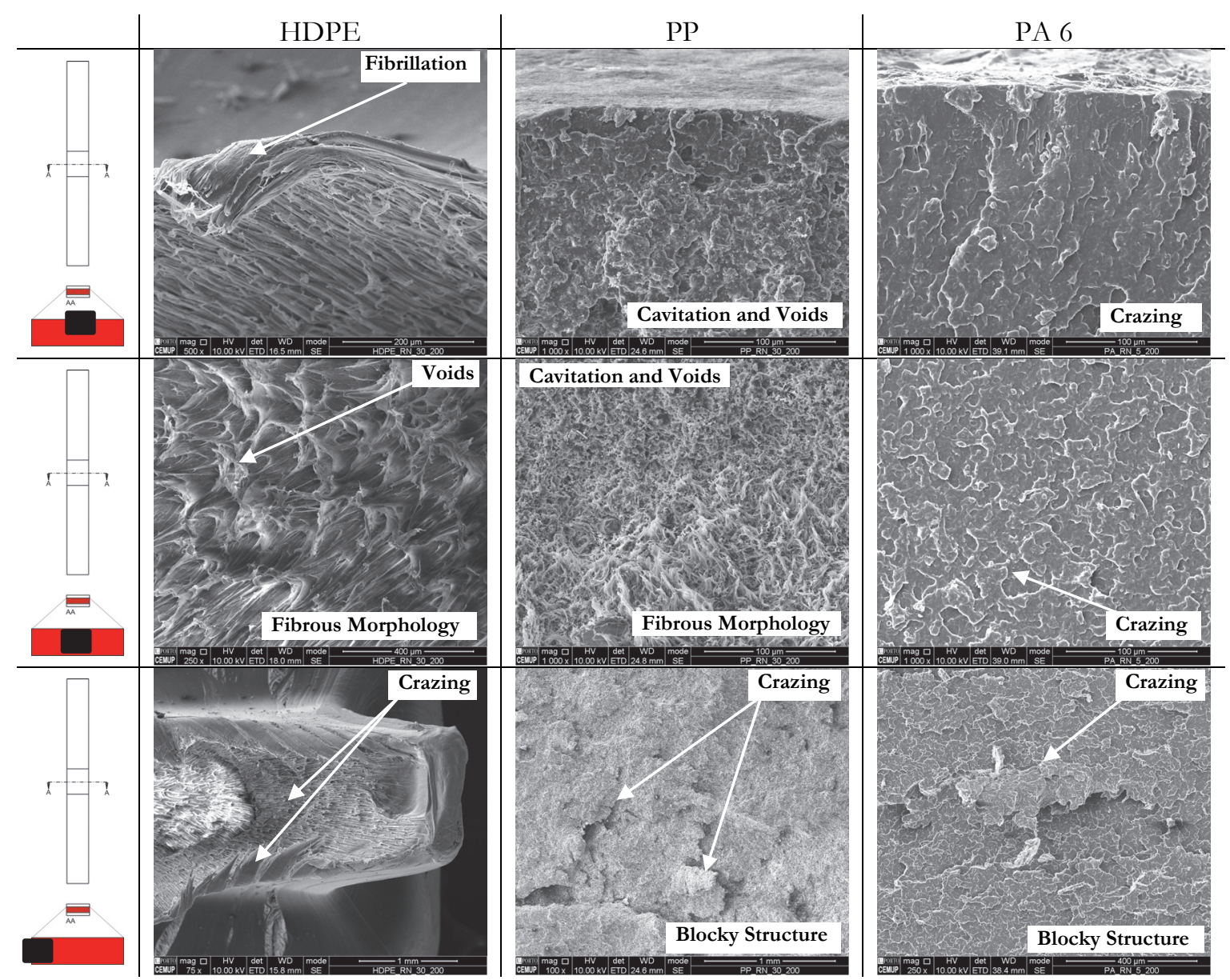

Figure 9: SEM fracture surfaces for flat notched specimens with $\mathrm{R}=30$, for HDPE, PP and PA 6. Note that in the first column, the geometry of specimen and fracture surface location are indicated by the black square.

SEM micrographs of PP exhibits rough surface patterns in fracture region, for $\mathrm{R}=5$. The predominantly brittle failure, cavitation and voids, are detected. Cavitation is the formation of voids (cavities) inside amorphous phase during deformation. It is often a precursor of brittle fracture or crazing and a common phenomenon in semi-crystalline polymers [32]. For PP flat notched specimens with $\mathrm{R}=30$, it is observed a mix of rough surface (cavitation and voids) with fibrous surface, in central region-fracture. In the extremities of flat notched specimen $\mathrm{R}=30$, the surface acquires a more inhomogeneous morphology, due to low stress triaxiality which causes the material flowing more extensively. A number of discontinuities or jumps in the fracture process leading to a blocky structure is observed. Considering that the inherent stress concentration is expected to be high in the mid thickness region, a stable crack nucleates and propagates through wedge 
and craze containing regions that grow inward from the surface leading to a blocky structure [30]. Brittle and crazing, are the two modes of fracture, observed for both notch radii. The effect of stress triaxiality slightly modifies the fracture surface and influences the void growth and size.

It is observed from SEM micrographs of PA 6, clearly different fracture surfaces, when compared with HDPE or PP. The fracture surface for specimen with $\mathrm{R}=5$ is smooth at the centre with some voids content and slight rough at the extremities, the last region to fracture, whereas the surface for the specimen with $\mathrm{R}=30$ is rough, with a very fine mesh and absence of fibrils formation. Some block structures are observed at near surface. Both fracture morphologies are an indicator of brittleness. Crazing and brittle fracture are the dominant modes of failure. Even though in PA 6 with specimens with R=5 the brittle fracture is smooth, occasionally spherical voids were observed, probably due to high stress triaxiality which induces the void formation [12]. Also, crazing mode of fracture occurred at some distance away from the centre. Even with the same specimen geometries, the fracture surface shows different morphologies. The fracture surface is slightly rough for PA 6, specimens with $\mathrm{R}=30$, more heterogeneous for PP and shows a filament like structure for HDPE.

\section{Analysis of Cylindrical Notched Specimens Fracture Morphologies under Tension at Stress Triaxialities between 0.39 and 0.64}

To explore the underlying fracture mechanisms under tension at crosshead speed of $200 \mathrm{~mm} / \mathrm{min}$ and at RT, SEM images were taken for the fracture surfaces of cylindrical notched specimens made of HDPE, PP and PA 6. Fracture surfaces of representative specimens with two different notch radii are displayed in Figs. 10 and 11.

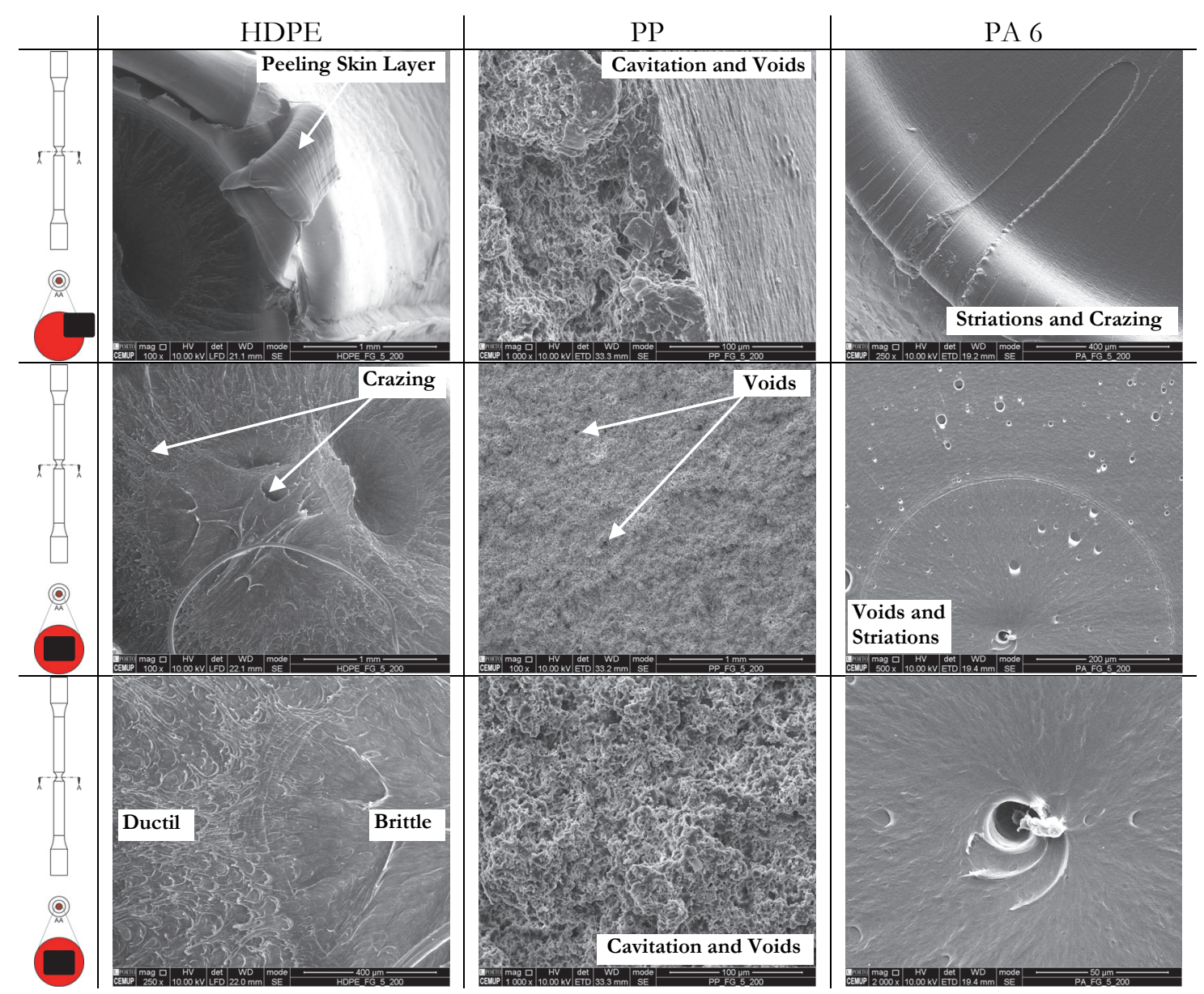

Figure 10: SEM fracture surfaces for cylindrical notched specimens with $\mathrm{R}=5$, for HDPE, PP and PA 6 . Note that in the first column the geometry of specimen and fracture surface location observation are indicated by the black square.

Laiarinandrasana et al. [12] discussed the effect of temperature, crosshead speed and stress triaxiality on the fracture of Polyvinylidene Fluoride (PVDF), a semi-crystalline polymer. To this end, tensile tests were performed on cylindrical notched specimens. It was reported more ductile fracture behaviour for specimens with larger notch radii (lower triaxialities), while increasing the stress triaxiality ratio (decreasing the notch radius) or increasing strain rate seems to favour the brittle fracture. 
This is in accordance with the experience from the present study. The HDPE and PA 6 cylindrical notched specimens, in particular the cylindrical geometry with $\mathrm{R}=30$ were too ductile to complete fracture, while the specimens with $\mathrm{R}=5$ were able to fully fracture the cross section in a brittle manner. The effect of stress triaxiality on fracture surface of PP is minimal however with increasing of notch radius seems to lead to a more ductile behaviour.

SEM micrographs of cylindrical notched specimens with notch radius $\mathrm{R}=5$ of HDPE showed two fracture morphologies: brittle fracture, where crack growth is supposed to be rapid and mix brittle/ductile fracture with some microfibrils content near surface, due to crazing fracture mechanism. The central fracture surface is less uneven than the fracture close to the material surface because the stress concentration is higher in the centre, probably from where the cracks nucleates and propagates. For $\mathrm{R}=30$ a uniform fibrillar structure over the cross section is visible, indicating that the fracture was ductile in nature, exhibiting enhanced ductility. The uniform fibrillar structure might be indicating that the surface layer had failed after void nucleation and multiple formation of microfibrils. At peripherical and central region, microfibrils with knobs or nodules with a smooth rounded surface like features probably formed by the relaxation of hot material, is observed. Similar features were found in research work performed by Brough et al. [33] on scanning electron micrographs of HDPE fracture surfaces. It is observed a large peeling skin for notched specimens with $\mathrm{R}=5$. The stress triaxiality rules the fracture morphology, which becomes more ductile with large fibril formation at low stress triaxiality (notch, $\mathrm{R}=30$ ), on the other hand becomes more brittle with increasing the stress triaxiality (notch, $\mathrm{R}=5$ ).

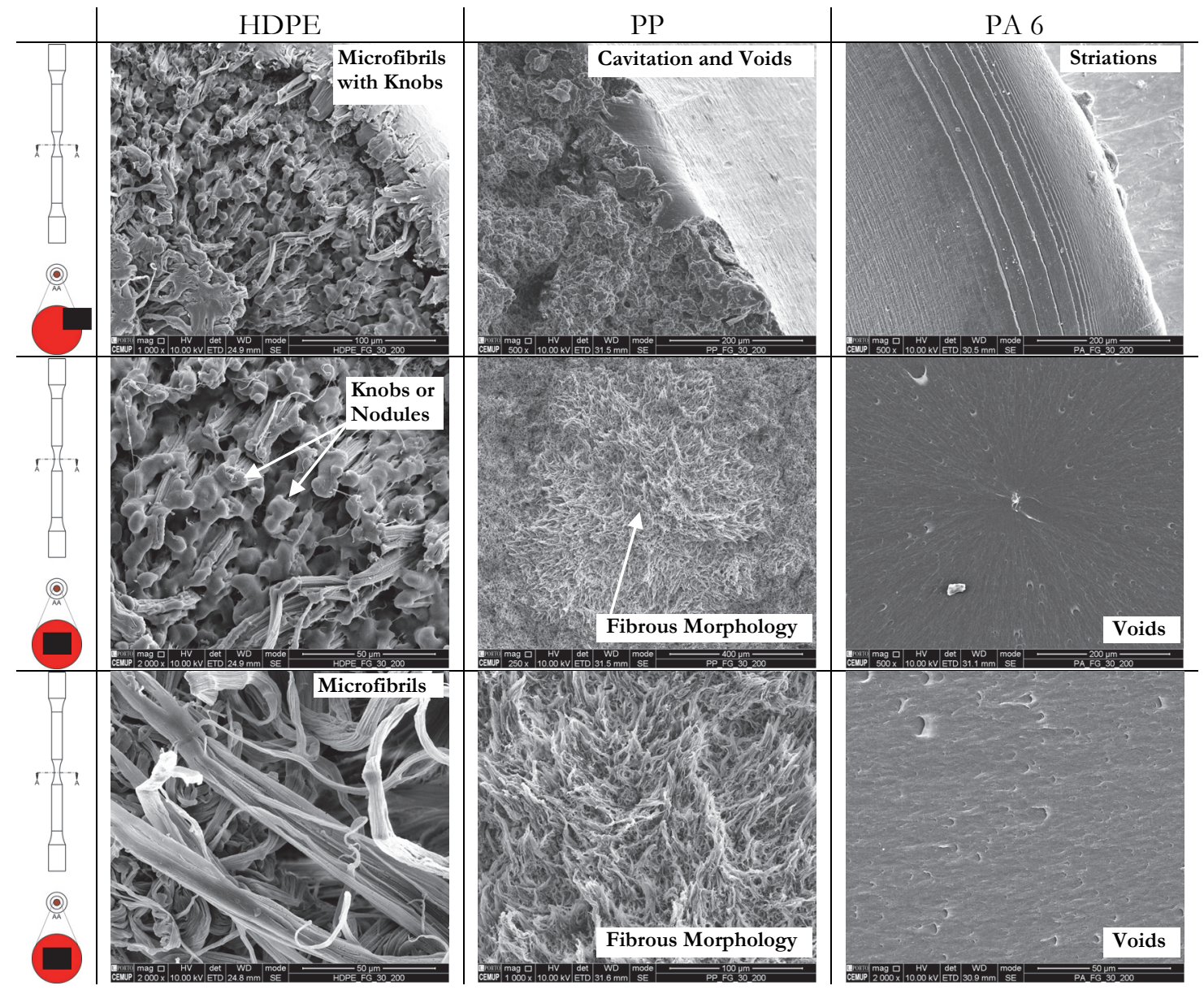

Figure 11: SEM fracture surfaces for cylindrical notched specimens with R=30, for HDPE, PP and PA 6. Note that in the first column the geometry of specimen and fracture surface observation location are indicated by the black square.

The fracture surface of PP for notch radius $\mathrm{R}=5$ exhibits a uniform fracture aspect, predominantly with rough surface, dominated by brittle fracture (cavitation and voids). Absence of fibrils formation is verified. In the case of the notched specimen with $\mathrm{R}=30$, there is a fibrillar structure, pulled out from the background surface, at the central fracture surface, which is consequence of low stress triaxiality. The fracture becomes more ductile. Similar to fracture morphology observation on PP flat notched specimens, also with cylindrical notched specimens, the effect of stress triaxiality slightly 
modifies the fracture surface and influences the void growth and size. Contrasting with the fracture surface of HDPE and PP, PA 6 features a "smooth surface" with radial striations and also some disperse cavitation/voids are detected in both notched radii, $R=5$ and $R=30$. The absence of fibrils formation is an indication of brittle fracture. The voids distribution density is higher at the specimen centre and decreases toward the specimen border. By comparing the two radii, the voids amount and size decrease with notch radius increasing (lower stress triaxiality ratio). Similar features on the mechanisms of void growth on cylindrical notched specimens were observed by Laiarinandrasana et al. [12]. In specimens with notch radius $\mathrm{R}=5$ the dominant mode of deformation near surface was crazing. An impression from comparing the fracture surfaces and the two notch radii of HDPE and PP specimens is that a higher radius causes a rougher fracture surface with higher fibrils formation. Therefore, the presence of notches (triaxial state of stress) change the fracture mechanism of the tested material from ductile (low stress triaxiality) to brittle (high stress triaxiality).

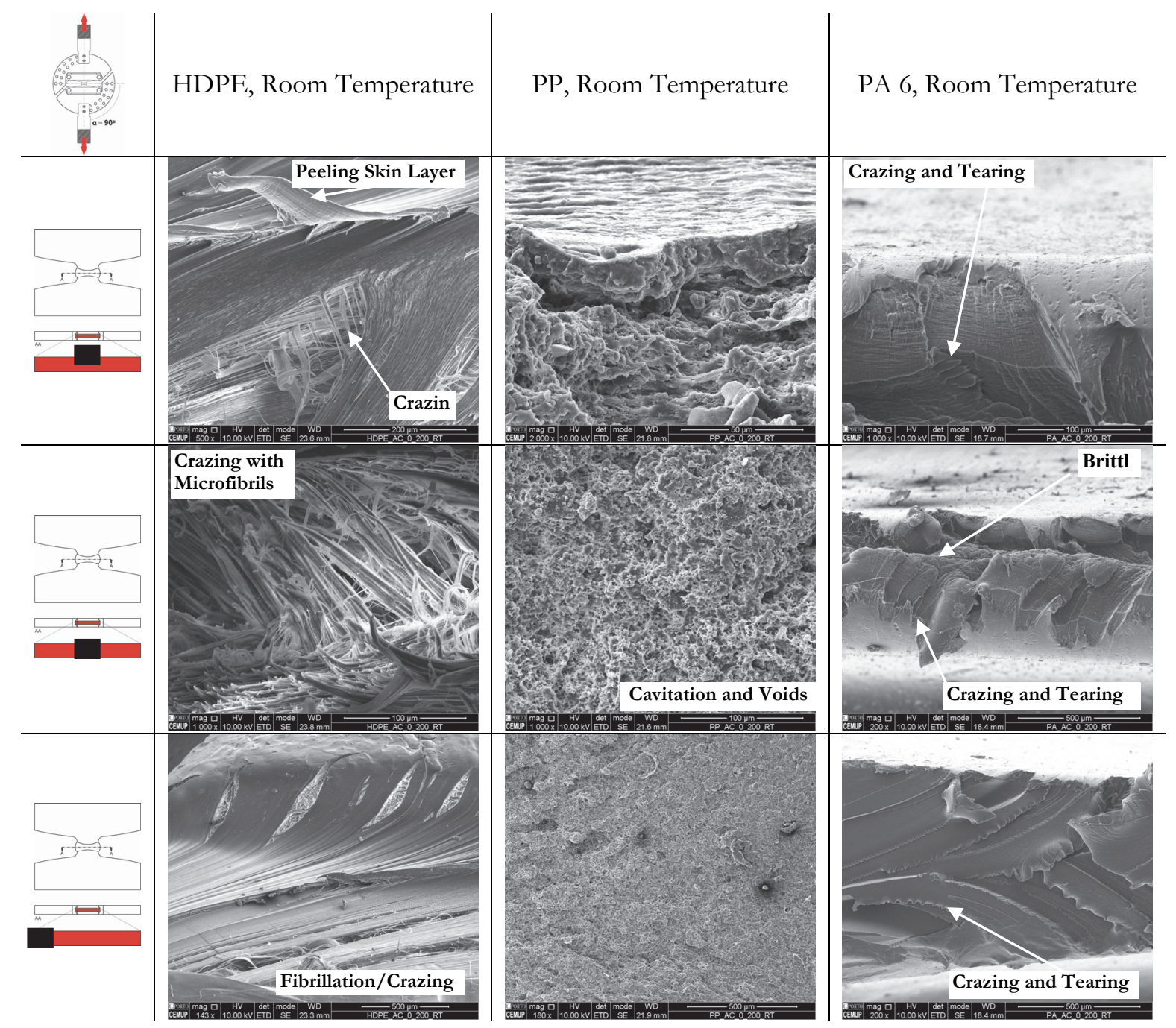

Figure 12: SEM images of butterfly specimens fractured for tensile loading at room temperature for HDPE, PP and PA 6. In the first column the geometry of specimen and fracture surface location are indicated by the black square.

\section{Analysis of Combined Tensile/ Shear Loading Fracture Morphologies at Stress Triaxialities between 0 and 0.58}

Fracture morphologies of butterfly specimens subjected to different loading angles of HDPE, PP and PA 6 materials were investigated with SEM. Due to the three loading angles $\left(\alpha=90^{\circ}, 30^{\circ}\right.$, and $\left.0^{\circ}\right)$ applied to the butterfly specimens at crosshead speed of $200 \mathrm{~mm} / \mathrm{min}$ and at two temperatures, RT and temperature of $50^{\circ} \mathrm{C}$, distinct fracture morphologies are generated for each material.

To explore the underlying fracture mechanisms under $\alpha=90^{\circ}$ (stress triaxiality $=0.58$ ) at room temperature and at temperature of $50^{\circ} \mathrm{C}$, for HDPE, PP and PA 6 SEM images were taken from the fracture surfaces and presented in Figs. 12 and 13, respectively. The fracture morphologies exhibit different modes of deformation for $\alpha=90^{\circ}$ at Room 
Temperature (Fig. 12). For HDPE, the plastic deformation occurs predominantly by a combination of crazing in the fracture surface centre and fibrillation/crazing type of fracture in the surface extremities, which is the last region to fracture. Also, a multiphase layer structure - "peeling skin layer" are shown in peripheric central region-fracture. The fractured skin layer behaves as a "peeling skin layer" and takes a form of high oriented fibrils or as massive craze and tearing [30].

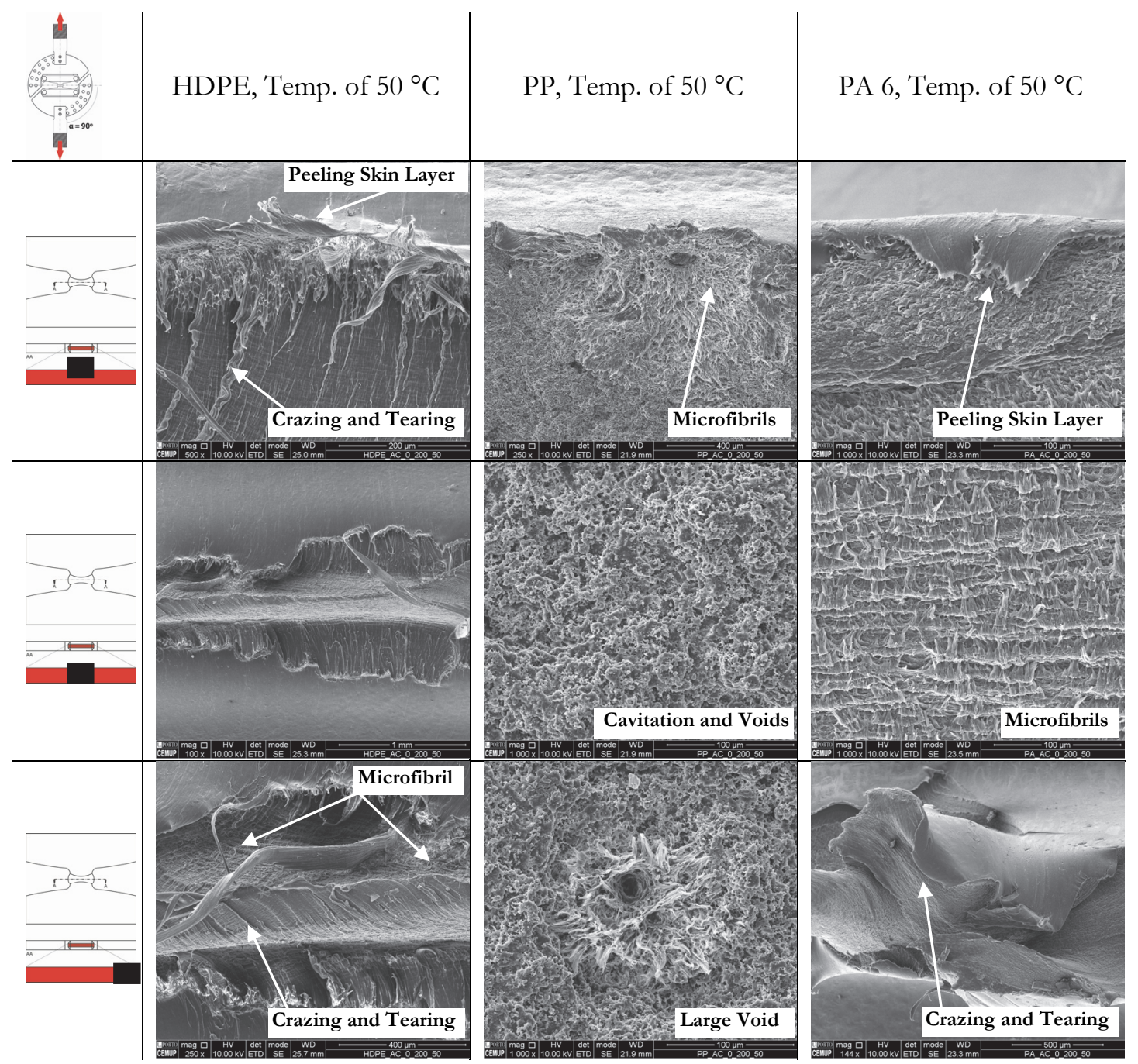

Figure 13: SEM images of butterfly specimens fractured for tensile loading at temperature of $50{ }^{\circ} \mathrm{C}$ for HDPE, PP and PA 6. In the first column the geometry of specimen and fracture surface location are indicated by the black square.

Considering that the inherent stress concentration is expected to be high in the middle section, crack nucleates and propagates through wedges. Fracture surface exhibits two main characteristics: ductile fracture associated with crazing at the centre from which fracture initiates; then, a transition area appears showing fibrillation type of fracture, associated with an extensive plastic flow, where crack growth is supposed to be rapid and last region of fracture. In the case of PP, the surface morphology displays an irregular surface with high void and cavitation content, which becomes rather rough and uneven at extremities; similar morphology was already observed on PP flat and cylindrical notched specimens. Brittle failure is the predominant fracture characteristic. A high inhomogeneous multiphase structure is exhibited by PA 6. It is observed that near surface the fracture takes a form of massive craze and tearing-crazing aspect. Dasari et al. [31] defined crazing and tearing, based on their observations made on in iPP-L (long chain high crystallinity polypropylenes) and HDPE fracture surfaces, as the initially crazes formation on the surface, with increase in strain, a crack nucleates and propagates inward through an array of crazes resulting tearing. The core region with high irregular fracture surface is characterized mainly by crazes and brittle failure. SEM micrographs at low magnification shows crazing and tearing in the region away from the centre of the fracture surface. It appears that the fracture initiated near the core of the butterfly specimen, and propagated 
outwards breaking through the crazed surface on both sides and extremities (resulting in tearing of the crazed region) at approximately the same position along the length of the section. Also, near surface inward growth of crazes from all the sides are observed. SEM images were also taken at a temperature of $50{ }^{\circ} \mathrm{C}$ and are shown in Fig. 13.

In general mode with increase in temperature, the fracture becomes more homogenous, the extent of craze region decreases and the ductile area/surface increases. In the case of HDPE, at central region, the fracture surface is reduced by neecking, becoming narrower, suggesting that was the last region to fracture. However, the fracture surface is more homogeneous. Also, it is observed, crazing and tearing with microfibrils formation and slope surfaces. High magnification of PP fracture surface shows irregular surface with high voids content; also at fracture extremities large voids surrounded by fibrils are observed. The fracture surface of PP does not undergo with major changes, with increasing the temperature. Even though the brittle failure is dominant, there is some evidence of ductile pulling of microfibrils around the voids at the edges. The "peeling skin layer" is observed in both HDPE and PP in peripheric central region-fracture. At a temperature of $50{ }^{\circ} \mathrm{C}, \mathrm{PA}$ 6 exhibits a fracture surface completely different from that obtained under room temperature. The fracture surface becomes more ductile with fibril formation at central region and more inhomogeneous at the extremities (the last region to fracture), with massive crazing and tearing formation.

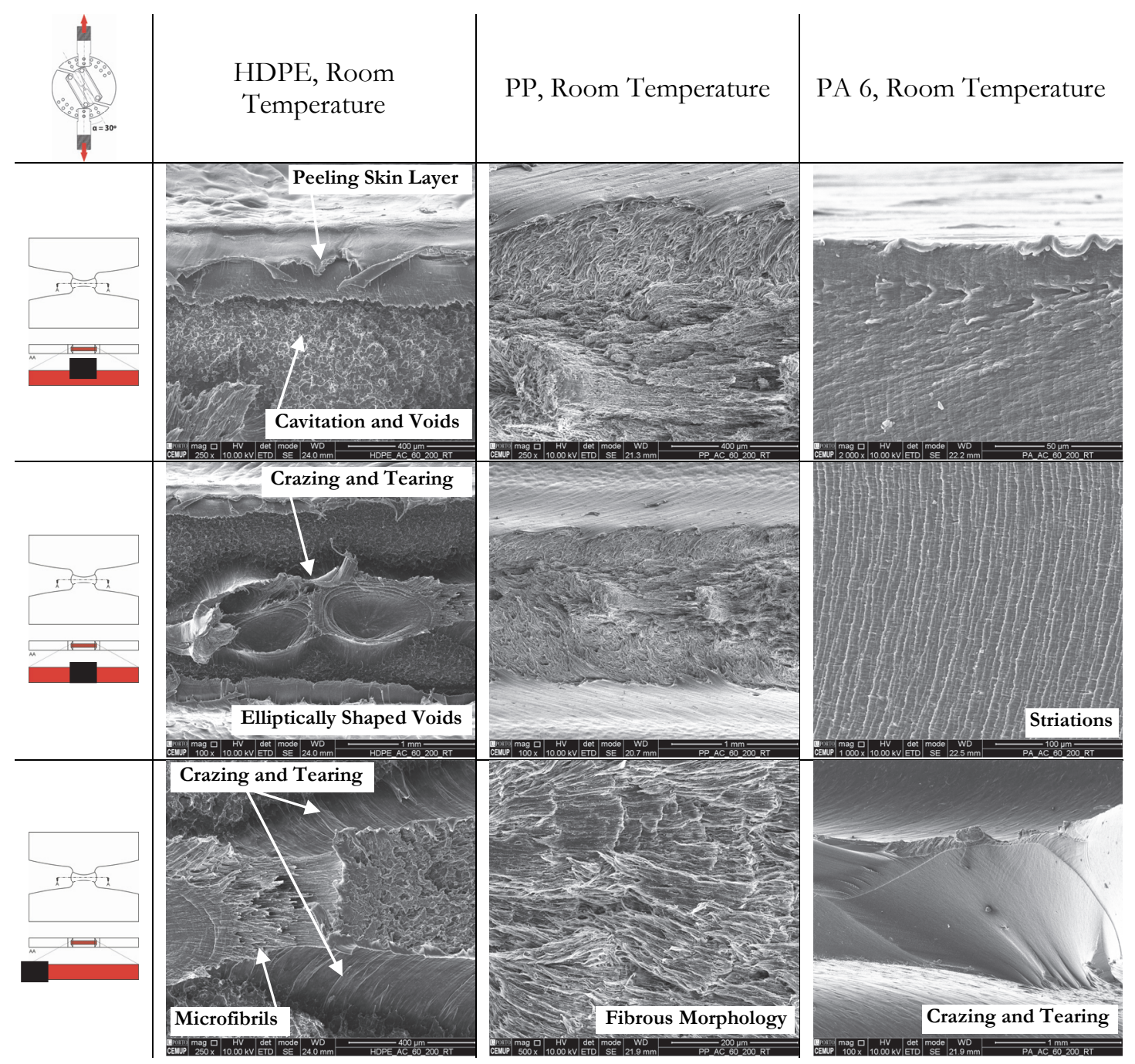

Figure 14: SEM images of butterfly specimens fractured for combined tensile/shear loading $\alpha=30^{\circ}$ at room temperature for HDPE, PP and PA 6. In the first column the geometry of specimen and fracture surface location are indicated by the black square.

SEM images of fracture surfaces of butterfly specimens tested under combined tension $/$ shear $\left(\alpha=30^{\circ}\right.$, stress triaxiality $=0.19$ ), at room temperature and temperature of $50^{\circ} \mathrm{C}$, for HDPE, PP and PA 6 , are displayed in Figs. 14 and 15 , respectively. At room temperature (Fig. 14), brittle fracture associated with large voids and cavitation, crazing and tearing associated to the combined tension/shear loading, with ductile pulling of microfibrils in the regions away from the centre 
of the fracture surface are the dominant plastic deformation for HDPE. In the central fracture surface of HDPE, two large ellipsoidal voids, surround by oriented fibrils morphology, are visible. The formation of elliptically shaped voids would be either due to plastically deformation inside amorphous phase or a pre-existing defect or even because the combined tension/shear loading (ellipse major axis in the shear direction). The fracture initiated in the centre and propagated towards the surface, where the fracture surface is characterized by crazing and tearing.

SEM micrographs of PP in the peripheric-central region show oriented fibrils with the direction of loading $\left(\alpha=30^{\circ}\right)$, exhibiting high deformation before failure (ductile failure). The inner layer shows a more ductile behaviour than at $\left(\alpha=90^{\circ}\right)$ and knobs or nodules are observed at the ends that might be caused by thermal softening. The fracture initiated in the outer layer and propagated towards the centre, justifying the presence of fibrous morphology elongations at centre. The centre of the fracture surface is characterized by extensive plastic flow around and inhomogeneous morphology. From PA 6 SEM micrographs, it is clear a brittle failure mode. At central fracture region, all surfaces are covered with a very fine mesh of striation configuration. SEM micrographs show crazing and tearing at the fracture surface end. The striations are a result of successive crack propagation increments. The striations are perpendicular to the shear loading.

At a temperature of $50{ }^{\circ} \mathrm{C}$ (Fig. 15), HDPE fracture surface becomes more regular, more homogeneous at the centre. Crazing and tearing as well as peeling skin layer are observed. The main fracture feature is the central slope formation, which propagated through the fracture length. Similar geometry was obtained for $\alpha=90^{\circ}$. Although crazing characterizes the ductile behaviour of a material, the central slope formation is considered to represent enhanced ductility (or plastic flow), consistent with decrease in fracture area.

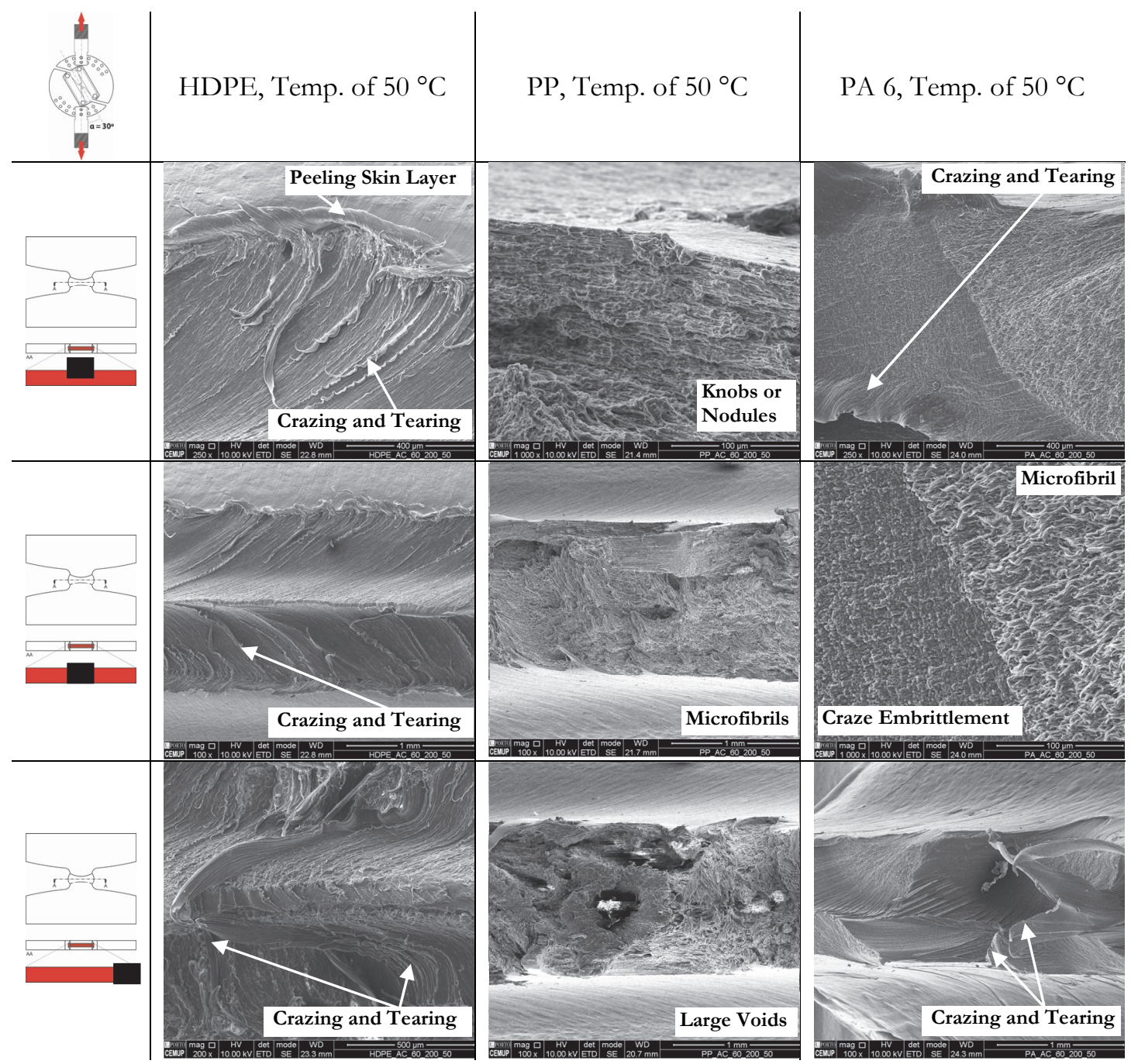

Figure 15: SEM images of butterfly specimens fractured for combined tensile/shear loading $\alpha=30^{\circ}$ at temperature of $50^{\circ} \mathrm{C}$ for $\mathrm{HDPE}$, $\mathrm{PP}$ and PA 6 . In the first column the geometry of specimen and fracture surface location are indicated by the black square. 
With temperature increase the fracture surface of PP exhibits an irregular aspect with microfibrils formation. The area fraction of fibrous morphology is increased with increase of temperature, with respected to RT. Large amount of deformation all over the area with a number of longer fibrils and large voids, also some evidence of thermal softening, are observed at fracture extremities. PA 6 SEM micrographs shows microfibrillar failure in the mid-thickness regions of the fracture surface versus craze embrittlement (brittle mode of failure due to high crosshead speed and temperature). The fracture surface becomes rougher and more irregular, with increasing the temperature. At extremities, the fracture surface shows high inhomogeneous surface. At this region, the fracture surface is characterized by crazing and tearing. Generally, in a tensile test, one expects the highest hydrostatic stress to be in the centre of the specimen and this could be the reason for the brittle fracture feature in the centre and more ductile in the longitudinal extremes.

SEM images of the fracture surfaces of the butterfly specimen loaded under pure shear $\left(\alpha=0^{\circ}\right.$, stress triaxiality: 0$)$ at room temperature and at temperature of $50^{\circ} \mathrm{C}$, for HDPE, PP and PA 6, are depicted in Figs. 16 and 17, respectively. At room temperature, HDPE and PP show a fracture surface predominantly of ductile type with crazing and tearing, and fibril formation associated with the shear loading. Pure shear leaves a relatively smooth fracture surface and orientated geometry.

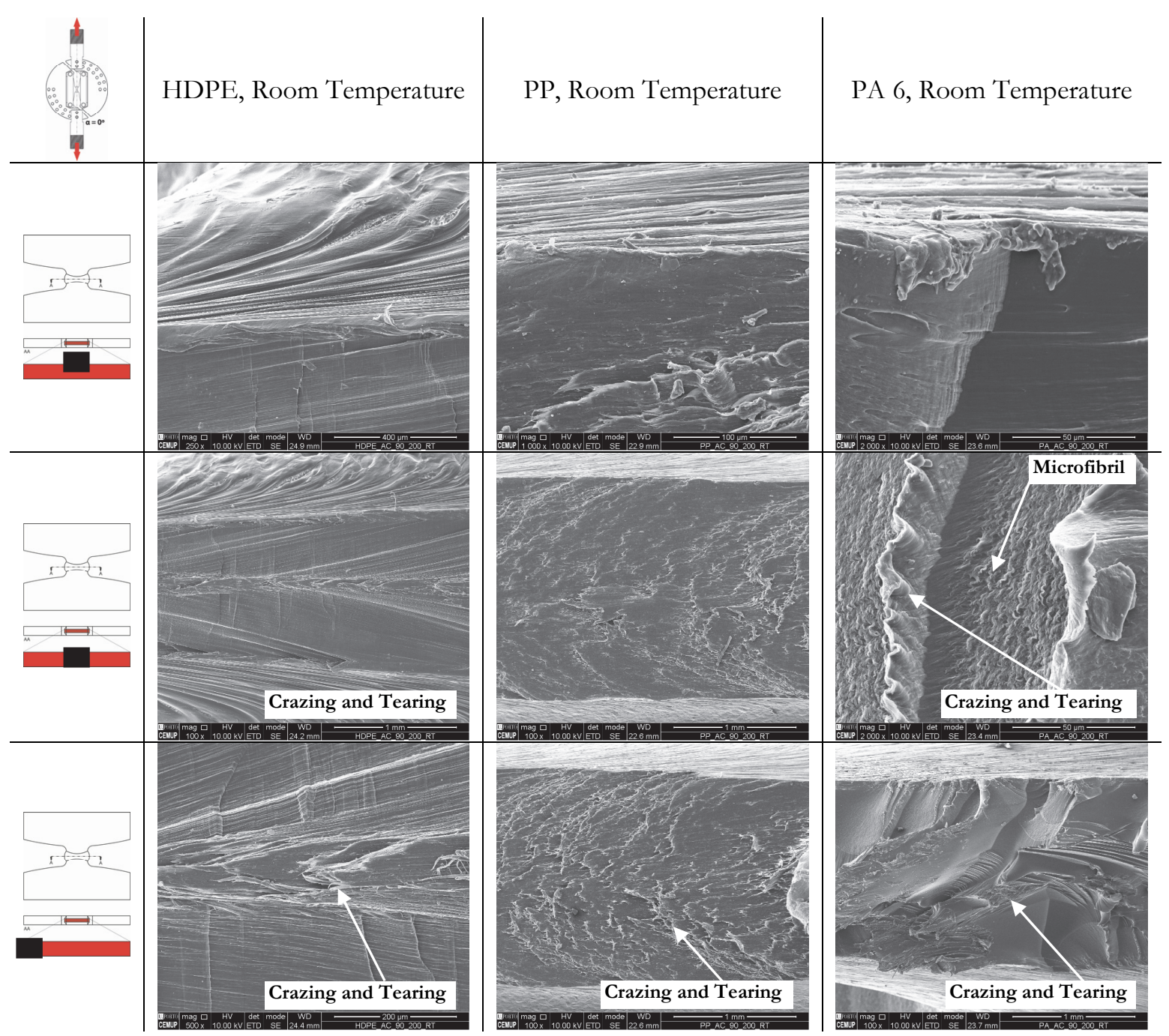

Figure 16: SEM images of butterfly specimens fractured for shear loading at room temperature for HDPE, PP and PA 6. In the first column the geometry of specimen and fracture surface location are indicated by the black square.

For PP, the fracture surface generated is particularly "clean" with a smooth surface in a form of waved structures, with fibril formation, along the shear stress direction, whereas in the case of HDPE a regular surface with almost geometric triangular patterns at the specimen centre is observed. Inside the fracture surface it is observed the fibrils formation and alignment. The symmetry suggests that the fracture starts near surface and propagates inwards through the crazed surface on both sides 
(resulting in tearing of the crazed region). PA 6 is the exception; SEM micrographs show a considerable plastic deformation and inhomogeneous morphology with significant localized deformation in the form of crazing tearing at the extremities and at the centre. At high magnification at central region, textured fracture surfaces are observed, with some fibrils formation and crazing tearing formation. At extremity, SEM micrographs shows some amount of microbuckling leading to a corrugated appearance in the regions away from the centre of the fracture surface.

At higher temperatures (Fig. 17) the polymer behaves in a much more viscous manner and the crazes widens very rapidly. The fracture surface seems to appear less rough and more homogeneous in the case of PP and PA 6. For HDPE, the regular surface with almost geometric triangular patterns, are elongated along the shear stress direction.

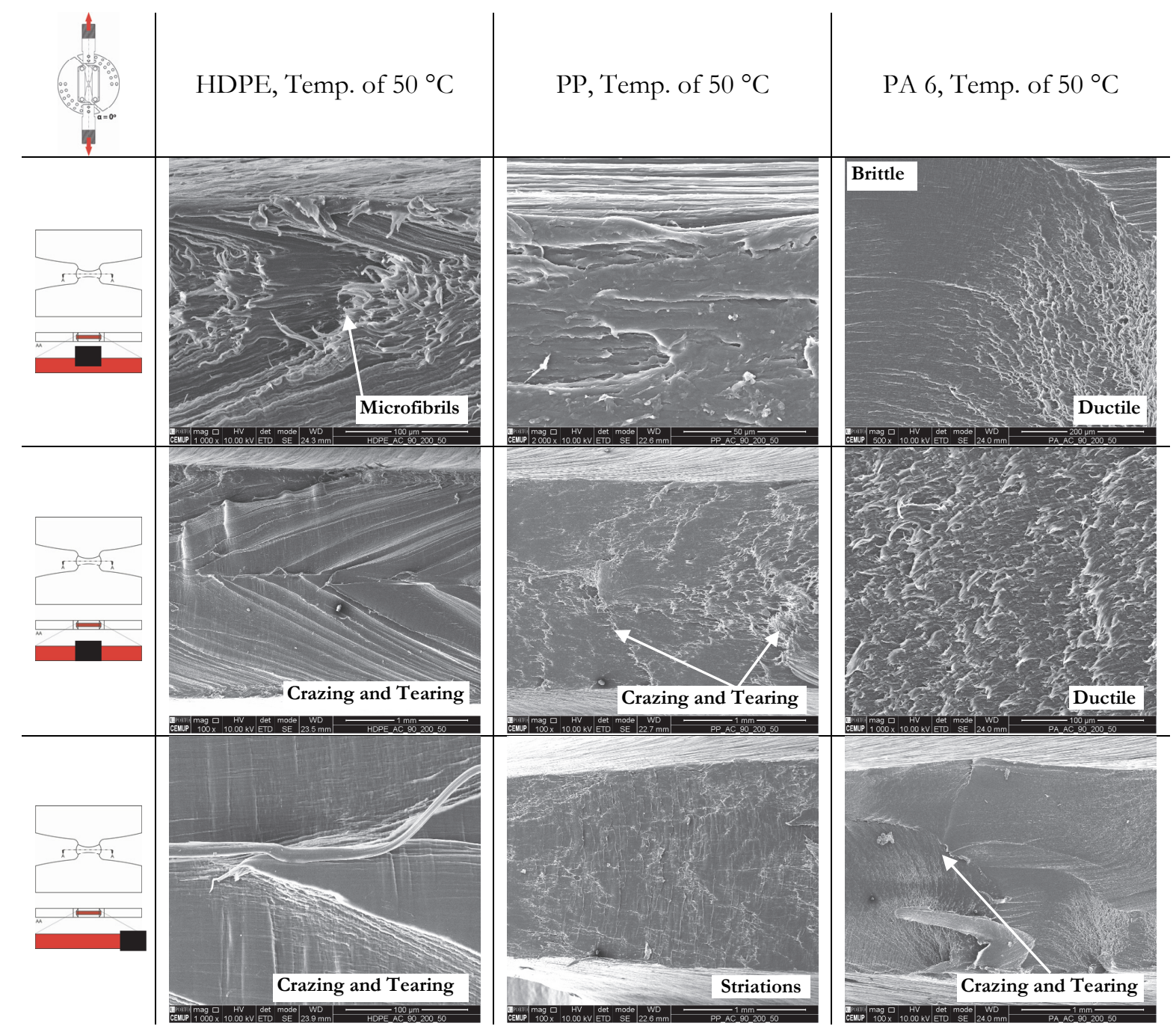

Figure 17: SEM images of butterfly specimens fractured for shear loading at temperature of $50{ }^{\circ} \mathrm{C}$ for HDPE, PP and PA 6. In the first column the geometry of specimen and fracture surface location are indicated by the black square.

HDPE fracture surfaces at RT and $50{ }^{\circ} \mathrm{C}$ have the same geometric patterns, however at $50{ }^{\circ} \mathrm{C}$ and at near surface appears a large number of microfibrils, indicating a continued plastically deformation as decohesion of crazing occurred. The dominant fracture is crazing, as well as for PP. PP fracture surface extremities show large areas covered with striations. The fracture surface is similar between RT and $50{ }^{\circ} \mathrm{C}$. In the shear deformation of PA 6 at $50{ }^{\circ} \mathrm{C}$ three fracture morphologies are identified: brittle with ductile pulling of microfibrils, crazing and shearing. The area fraction of brittle failure decreased with increase in temperature with consequent increase in ductile fracture. 


\section{CONCLUSIONS}

$\mathrm{F}$ rom the experimental tests, one can conclude that, the yield load in the lowest testing speed occurs at higher displacements, because the polymer macromolecules have the time necessary to induce an orderly alignment. At higher crosshead speeds, increases both the propensity of the material to form a clear and higher yield load at lower displacement values and the material exhibits a more brittle behaviour. In tensile tests of notched specimens, the yield load increases with decreasing the specimen notch radii (increasing the stress triaxiality), while the corresponding displacement decreases. The smaller the notch radius, the higher the stress triaxiality is. It was observed that the specimens gradually started to whiten, near the yield load. As the plastic deformation continued, the stress whitening became clearer and sets the shape changes (dilatation), due to the formation of microvoids. With ongoing deformation, localisation grows to extremes, resulting in void nucleation, void growth, craze formation and catastrophic failure.

From the experimental tests, one can conclude that, at RT the drop of the load with the biaxial loading angle attains a maximum value for the loading angle $\alpha=0^{\circ}$ (pure shear) and minimum for $\alpha=90^{\circ}$ (pure tension). The higher the loading angle, higher is the load required to deform the specimens. The load-displacement curves shift to higher load values with increase of crosshead speed. The plastic stiffness decreases with increasing of crosshead speed for all loading angles. The crosshead speed and loading angle "after yielding" play a key role in the macroscopic deformation behaviour and determine whether the material behaves as brittle or ductile. Decreasing crosshead speed and increasing temperature results in lowering of the load needed to reach a given displacement. Therefore, the yield load shows an explicit dependency on temperature and crosshead speed. Increase of temperature and reduction in crosshead speed lead to a more ductile behaviour. The occurrence of stress whitening in HDPE was found to be dependent upon the temperature and strain rate.

The load-displacement curves show that semi-crystalline polymers used at temperatures above $T_{\mathrm{g}}$, such as PA 6, becomes more stables. HDPE is chemically the closest in structure to PP, therefore similarities in load-displacement curves, are observed. However, HDPE exhibits better mechanical properties.

In flat and cylindrical notched specimens, it is assumed that the fracture toughness of semi-crystalline polymers is controlled by mechanisms such as crazing, void and cavitation formation. One of the major factors controlling the occurrence of yielding or brittle fracture is the state of stress, such as the one included by the presence of notches. HDPE and PP were deformed at temperatures above the glass transition. SEM fracture morphologies of HDPE, PP and PA 6, reveal that the fracture morphologies are highly dependent on stress states. Lower stress triaxiality is a synonymous of ductile fracture. Flat notched specimens, $\mathrm{R}=5$ and $\mathrm{R}=30$, show the formation of an oriented texture of fibrous surface, which increases with decrease of notched radii (low triaxiality). It is observed that rising the stress triaxiality, fracture becomes more brittle and homogeneous, with less propensity for the formation of longer fibrous surface and more voids content. Qualitative SEM observations of HDPE, PP and PA 6 fracture surfaces of flat and cylindrical notched specimens depict inhomogeneous morphology. Mechanisms such as crazing, void and cavitation formation, are observed. In the same surfaces two or more mechanisms, are found. This means that the stress across fracture surface is not equal and is maximum at centre, where the fracture normally begins (large triaxiality). In cylindrical notched specimens, the voids are larger near to the specimen axis, where the stress triaxiality ratio is high, and its distribution density is higher at the specimen centre and decreases toward the specimen border. By comparing the two radii, the voids amount and size decreases as the notch radius increase (lower stress triaxiality ratio). Although the different stress triaxialities imposed by different specimen's geometries and notches, the fracture surfaces morphologies slight modifies for PP. This feature might be attributed to the internal morphology of polymer. In HDPE cylindrical notched specimens and $\mathrm{R}=30$ at peripherical and central region microfibrils with knobs or nodules with a smooth rounded surface like features, probably formed by the relaxation of hot material, was observed.

The microstructure deformation mechanisms of butterfly specimens loaded at $\alpha=90^{\circ}$ - tension, room temperature and at temperature of $50^{\circ} \mathrm{C}$, for HDPE, PP and PA 6 , show that the fracture morphology exhibits different modes of deformation, mechanisms such as crazing, voids and cavitation formation being observed. Two or more mechanisms are predominant and fracture morphology are inhomogeneous. The inherent stress concentration is expected to be high in the middle section, thus crack nucleates and propagates through wedges. In general, with the increase in temperature, fracture becomes more homogenous, the extent of craze region decreasing and the ductile area/surface increasing. In the case of HDPE, at the central region, the fracture surface is reduced, becoming narrower, suggesting that was the last region to fracture. PA 6 acquires a fracture surface completely different from that obtained with room temperature. With increasing temperature, the fracture surface becomes more ductile with fibril formation at central region.

In combined tensile/shear $\left(\alpha=30^{\circ}\right)$ it is observed a fracture morphology oriented towards the loading direction, such as in the case of $\mathrm{PP}$, which at RT or at temperature of $50^{\circ} \mathrm{C}$ show oriented fibrils with the direction of loading $\left(\alpha=30^{\circ}\right)$, 
exhibiting high deformation before failure (ductile failure). The inner layer shows a more ductile behaviour than at $\alpha=90^{\circ}$. Different fracture morfologies are observed, when compared with $\alpha=90^{\circ}$. The fracture becomes more ductile and less homogeneous, with more formation propensity of longer fibrous surface. Also, with the temperature increase, fracture becomes more homogenous.

SEM images of fracture mechanisms under pure shear, $\alpha=0^{\circ}$, leaves a relatively smooth fracture surface and orientated geometry. In general, it is observed that the fibrils are oriented towards the shear direction. With the temperature increase, fracture becomes more homogenous in the case of PA 6 and slightly inhomogeneous for PP and PA 6.

\section{ACKNOWLEDGMENTS}

$\mathrm{T}$ he present research work has been financial supported through the NORTE-01-0145-FEDER-000022 - SciTech Science and Technology for Competitive and Sustainable Industries, I\&D project co-funded by Programa Operacional Regional do Norte ("NORTE2020"), through the Fundo Europeu de Desenvolvimento Regional (FEDER) and by FCT (Fundação para a Ciência e a Tecnologia) under a PhD grant with reference PD/BD/52346/2013 are gratefully acknowledged. This work was funded by National Funds through FCT - Fundação para a Ciência e a Tecnologia in the scope of project MITP-TB/PFM/0005/2013.

\section{REFERENCES}

[1] Sedighiamiri, A., Govaert, L.E., Van Dommelen, J.A.W. (2011). Micromechanical Modeling of the Deformation Kinetics of Semicrystalline Polymers, J. Polym. Sci. Part B Polym. Phys., 49(18), pp. 1297-1310. DOI: $10.1002 /$ polb.22297.

[2] Galeski, A. (2003). Strength and Toughness of Crystalline Polymer Systems, Prog. Polym. Sci., 28(12), pp. 1643-1699. DOI: 10.1016/j.progpolymsci.2003.09.003.

[3] Narisawa, I., Ishikawa, M. (1990). Crazing in Semicrystalline Thermoplastics, Crazing Polym. 2(2), pp. 353-391. DOI: $10.1007 / \mathrm{BFb} 0018025$.

[4] Bai, Y. (2008). Effect of Loading History on Necking and Fracture, PhD Thesis, (2000), pp. 1-262.

[5] Bridgman, P.W. (1923). The Compressibility of Thirty Metals as a Function of Pressure and Temperature, Proc. Am. Acad. Arts Sci., 58(5), pp. 165-242.

[6] Estevez, R., Tijssens, M.G.A., Van Der Giessen, E. (2000). Modeling of the Competition Between Shear Yielding and Crazing in Glassy Polymers, J. Mech. Phys. Solids, 48(12), pp. 2585-2617. DOI: 10.1016/S0022-5096(00)00016-8.

[7] Tijssens, M.G.A., Van Der Giessen, E., Sluys, L.J. (2000). Modeling of Crazing Using a Cohesive Surface Methodology, Mech. Mater., 32(1), pp. 19-35. DOI: 10.1016/S0167-6636(99)00044-7.

[8] Hachour, K., Zairi, F., Naït-Abdelaziz, M., Gloaguen, J.M., Aberkane, M., Lefebvre, J.M. (2014). Experiments and Modeling of High-Crystalline Polyethylene Yielding Under Different Stress States, Int. J. Plast., 54, pp. 1-18. DOI: 10.1016/j.ijplas.2013.06.004.

[9] Mark, J.E. (2009). Polymer Data Handbook, Oxford University Press.

[10] Faleskog, J., Barsoum, I. (2013). Tension-Torsion Fracture Experiments - Part I: Experiments and a Procedure to Evaluate the Equivalent Plastic Strain, Int. J. Solids Struct., 50(25-26), pp. 4241-4257.

DOI: 10.1016/j.ijsolstr.2013.08.029.

[11] Boisot, G., Laiarinandrasana, L., Besson, J., Fond, C., Hochstetter, G. (2011). Experimental Investigations and Modeling of Volume Change Induced by Void Growth in Polyamide 11, Int. J. Solids Struct., 48(19), pp. 2642-2654. DOI: 10.1016/j.ijsolstr.2011.05.016.

[12] Laiarinandrasana, L., Besson, J., Lafarge, M., Hochstetter, G. (2009). Temperature Dependent Mechanical Behaviour of PVDF: Experiments and Numerical Modelling, Int. J. Plast., 25(7), pp. 1301-1324.

DOI: $10.1016 /$ j.ijplas.2008.09.008.

[13] Dunand, M., Mohr, D. (2011). Optimized Butterfly Specimen for the Fracture Testing of Sheet Materials Under Combined Normal and Shear Loading, Eng. Fract. Mech., 78(17), pp. 2919-2934.

DOI: 10.1016/j.engfracmech.2011.08.008.

[14] Doyoyo, M., Wierzbicki, T. (2003). Experimental Studies on the Yield Behavior of Ductile and Brittle Aluminum Foams, Int. J. Plast., 19(8), pp. 1195-1214. DOI: 10.1016/S0749-6419(02)00017-7.

[15] Arcan, M., Hashin, Z., Voloshin, A. (1978). A Method to Produce Plane-Stress States with Applications to Fiber- 
Reinforced Materials, Exp. Mech., pp. 141-146.

[16] Mohr, D., Doyoyo, M. (2002). Analysis of the Arcan Apparatus in the Clamped Configuration, J. Compos. Mater., 36(22), pp. 2583-2594. DOI: 10.1106/002199802027874.

[17] FEI Company. (2008). Quanta 3D FEG User Operation Manual, , pp. 1-192.

[18] European Committee for Standardization (CEN). (n.d.). EN ISO 527-1:1993 Plastics - Determination of Tensile Properties.

[19] Pawlak, A., Galeski, A., Rozanski, A. (2014). Cavitation During Deformation of Semicrystalline Polymers, Prog. Polym. Sci., 39(5), pp. 921-958. DOI: 10.1016/j.progpolymsci.2013.10.007.

[20] Fouad, H. (2010). Experimental and Numerical Studies of the Notch Strengthening Behaviour of Semi-Crystalline Ultra-High Molecular Weight Polyethylene, Mater. Des., 31(3), pp. 1117-1129. DOI: 10.1016/j.matdes.2009.09.042.

[21] Bartczak, Z., Galeski, A. (2010). Plasticity of Semicrystalline Polymers, Macromol. Symp., 294(1), pp. 67-90. DOI: $10.1002 /$ masy.201050807.

[22] Humbert, S., Lame, O., Chenal, J.M., Rochas, C., Vigier, G. (2010). New Insight on Initiation of Cavitation in Semicrystalline Polymers: In-situ SAXS Measurements, Macromolecules, 43(17), pp. 7212-7221.

DOI: $10.1021 / \mathrm{ma101042d.}$

[23] Viana, J.C. (2005). Structural Interpretation of the Strain-Rate, Temperature and Morphology Dependence of the Yield Stress of Injection Molded Semicrystalline Polymers, Polymer (Guildf), 46, pp. 11773-11785.

DOI: $10.1016 /$ j.polymer.2005.10.024.

[24] Zhou, H., Wilkes, G.L. (1998). Orientation-Dependent Mechanical Properties and Deformation Morphologies for Uniaxially Melt-Extruded High-Density Polyethylene Films Having an Initial Stacked Lamellar Texture, J. Mater. Sci., 33, pp. 287-303. DOI: 10.1023/a:1004351209140.

[25] Wattrisse, B., Muracciole, J.M., Chrysochoos, A. (2002). Thermomechanical Effects of Accompanying the Localized Necking of Semi-Crystalline Polymers, Int. J. Therm. Sci., 41(5), pp. 422-427. DOI: 10.1016/S1290-0729(02)01334-0.

[26] Hartmann, B., Lee, G.F., Wong, W. (1987). Tensile Yield in Polypropylene, Polym. Eng. Sci., 27(11), pp. 823-828. DOI: $10.1002 /$ pen.760271109.

[27] Arruda, E.M., Boyce, M.C., Jayachandran, R. (1995). Effects of Strain Rate, Temperature and Thermomechanical Coupling on the Finite Strain Deformation of Glassy Polymers, Mech. Mater., 19(2-3), pp. 193-212. DOI: 10.1016/0167-6636(94)00034-E.

[28] Chanda, M., Roy, S.K. (2008). Plastics Fundamentals, Properties and Testing, CRC press.

[29] Peacock, A. (2000). Handbook of Polyethylene, Structures, Properties, and Applications, Marcel Dekker.

[30] Dasari, A., Misra, R.D.K. (2003). On the strain rate sensitivity of high density polyethylene and polypropylenes, Mater. Sci. Eng. A, 358(1-2), pp. 356-371. DOI: 10.1016/S0921-5093(03)00330-7.

[31] Dasari, A., Rohrmann, J., Misra, R.D.K. (2003). Microstructural Evolution During Tensile Deformation of Polypropylenes, Mater. Sci. Eng. A, 351(1-2), pp. 200-213. DOI: 10.1016/S0921-5093(02)00854-7.

[32] Pawlak, A. (2007). Cavitation During Tensile Deformation of High-Density Polyethylene, Polymer (Guildf)., 48(5), pp. 1397-409. DOI: 10.1016/j.polymer.2006.12.054.

[33] Brough, I., Haward, R.N., Healey, G., Wood, A. (2004). Scanning Electron Micrographs of High Density Polyethylene Fracture Surfaces, Polymer (Guildf), 45(10), pp. 3115-3123. DOI: 10.1016/j.polymer.2004.02.036. 